\title{
An Ocean Modeling Study To Quantify Wind Forcing and Oceanic Mixing Effects on The Tropical North Pacific Subsurface Warm Bias in CMIP and OMIP Simulations
}

\section{Yuchao Zhu}

Institute of Oceanology Chinese Academy of Sciences

Rong-Hua Zhang ( $\sim$ rzhang@qdio.ac.cn)

Institue of Oceanology, Chinese Academy of Sciences https://orcid.org/0000-0002-3332-7849

Delei Li

Institute of Oceanology Chinese Academy of Sciences

\section{Research Article}

Keywords: Model errors, Subsurface temperature bias, CMIP/OMIP simulations, Vertical mixing scheme, Wind forcing errors

Posted Date: February 18th, 2021

DOI: https://doi.org/10.21203/rs.3.rs-204857/v1

License: (c) (i) This work is licensed under a Creative Commons Attribution 4.0 International License.

Read Full License

Version of Record: A version of this preprint was published at Climate Dynamics on September 5th, 2021. See the published version at https://doi.org/10.1007/s00382-021-05946-y. 

An ocean modeling study to quantify wind forcing and oceanic mixing effects on the tropical North Pacific subsurface warm bias in CMIP and OMIP simulations

Yuchao Zhu ${ }^{1,2}$, Rong-Hua Zhang ${ }^{* 1,2,3,4}$ and Delei $\mathrm{Li}^{1,2}$

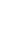

${ }^{1}$ CAS Key Laboratory of Ocean Circulation and Waves, Institute of Oceanology, and Center for Ocean Mega-Science, Chinese Academy of Sciences, Qingdao, 266071, China;

${ }^{2}$ Pilot National Laboratory for Marine Science and Technology (Qingdao), Qingdao, China;

${ }^{3}$ Center for Excellence in Quaternary Science and Global Change, Chinese Academy of Sciences,

Xian 710061, China;

${ }^{4}$ University of Chinese Academy of Sciences, Beijing, China;

\section{Corresponding author address:}

Rong-Hua Zhang, Key Laboratory of Ocean Circulation and Waves, Institute of Oceanology,

Chinese Academy of Sciences, Qingdao 266071, China

Email: rzhang@qdio.ac.cn 
Abstract

Sea surface temperature (SST) bias in the climate models has been a focus in the past, but subsurface temperature biases have not been received much attention yet. In this study, subsurface temperature biases in the Tropical North Pacific (TNP) are investigated by analyzing the CMIP6, CMIP5 and OMIP products, and performing ocean model simulations. It is found that almost all the CMIP and OMIP simulations have a pronounced subsurface warm bias (SWB) in the northeastern tropical Pacific (NETP), and the model developments over the past decade do not indicate obvious improvements in bias pattern and magnitude from CMIP5 to the latest version CMIP6. This SWB is primarily caused by the model deficiencies in the simulated surface wind stress curl (WSC) in the NETP, which is too weak to produce a sufficient Ekman upwelling, a bias that also exists in OMIP simulations. The uncertainties in the parameterizations of the oceanic vertical mixing processes also make a great contribution, and it is demonstrated that the estimated oceanic vertical diffusivities are overestimated both in the upper boundary layer and the interior in the CMIP and OMIP simulations. The relationship between the SWB and the misrepresented oceanic vertical mixing processes are investigated by conducting several ocean-only experiments, in which the upper boundary layer mixing is modified by reducing the wind stirring effect in the KrausTurner type bulk mixed-layer approach, and the interior mixing is 
constrained by using the Argo-derived diffusivity. By applying these modifications to oceanic vertical mixing schemes, the SWB is greatly reduced in the NETP. The consequences of this SWB are further analyzed. Because the thermal structure in the NETP can influence the simulations of oceanic circulations and equatorial upper-ocean thermal structure, the large SWB in the CMIP6 models tends to produce a weak equatorward water transport in the subsurface TNP, a weak equatorial upwelling and a warm equatorial upper ocean.

Keywords: Model errors; Subsurface temperature bias; CMIP/OMIP 54 simulations; Vertical mixing scheme; Wind forcing errors 


\section{Introduction}

Understanding climate model biases is critically important for the assessments of future climate change, and hence "What are the origins and consequences of systematic model biases?" is one of the three key scientific issues have been addressed in CMIP6 (Eyring et al., 2016). Given the important role played by sea surface temperature (SST) in air-sea coupling, SST biases in climate models have received considerable attention in the past. For example, the too cold tongue bias along the equatorial Pacific can be attributed to the misrepresented oceanic vertical turbulent mixing processes along the equator (Jochum, 2009; Sasaki et al., 2013; Furue et al., 2015; Jia et al., 2015; Zhu and Zhang, 2018b, 2019), overestimated cloud albedo in the subtropics (Burls et al., 2017; Thomas and Fedorov, 2017), uncertainties in the atmospheric convection parameterizations (Woelfle et al., 2018), and so on. The warm SST bias in the southeastern tropical Pacific and Atlantic can be attributed to coarse resolutions of climate models (Seo et al., 2006; Small et al., 2014), uncertainties in the parameterizations of atmospheric convection and cloud physics (Ma et al., 1996; Gordon et al., 2000), and eastward propagation of equatorial subsurface warm bias (Xu et al., 2014). SST biases can severely degrade the credibility of climate predictions and projections. For example, too cold tongue bias in the equatorial Pacific promotes a La Niñalike warming pattern in the tropical Pacific under the increasing 
concentrations of greenhouse gases, whereas an El Niño-like warming pattern is produced when the too cold tongue bias is removed from model projections (Li et al., 2016; Ying et al., 2019).

Thermal structure and variability in the subsurface oceans are known to play an important role in the climate change. For example, the acceleration of ocean subsurface warming and the slowdown of surface warming in the early decade of the 21 st century indicate that deep oceans play a critical role in regulating the global warming (Chen and Tung, 2014; Wang et al., 2018). However, compared with that at sea surface, temperature bias in the subsurface oceans is poorly understood. Therefore, it is essential to investigate the oceanic subsurface temperature bias for understanding the simulations and predictions of global energy and heat redistribution. Particularly, subsurface temperature simulation in the tropics is very important to the climate simulations. For instance, $\mathrm{Xu}$ et al. (2014) find that the subsurface warm bias within the Atlantic equatorial thermocline can be transported to the Benguela coast by horizontal currents and subsequently surfaces by coastal upwelling, contributing to the longstanding warm SST bias in the eastern tropical Atlantic. In addition, subsurface warm temperature bias along the Pacific equator generates a too diffuse equatorial thermocline, leading to a weak SST-thermocline feedback in the tropical air-sea coupling (Guilyardi et al., 2009; Gao and Zhang, 2017; Zhang et al., 2020). Off the equator, subsurface temperature 
bias in the climate models is of the opposite sign in the north and south tropical Pacific: a large warm bias between $5^{\circ}-10^{\circ} \mathrm{N}$ and a large cold bias near $10^{\circ} \mathrm{S}$ (Wittenberg et al., 2006; Zhu et al., 2020a). Though being substantial in its magnitude, the subsurface temperature bias off the equator has not been receive much attention yet. Importantly, owing to the local Ekman pumping in the Tropical North Pacific (TNP), climatological pycnocline tends to arise to form a potential vorticity barrier, acting to block the local water exchange between the subtropics and tropics ( $\mathrm{Lu}$ and McCreary, 1995; Rothstein et al., 1998; Johnson and McPhaden, 1999). In this way, the subsurface warm bias in the TNP acts to weaken the potential vorticity barrier, and would affect the width of subtropical-tropical water exchange window.

Subsurface temperature bias also reflects an erroneous representation of oceanic vertical heat distribution in climate models. Thus, in addition to the poorly simulated atmospheric forcing, flaws in ocean models might be an important source of subsurface temperature bias. One simulation flaw is associated with the oceanic mesoscale eddies, which act to transport heat upward and offset the downward heat transport; these processes are unsolved in coarse resolution models. By increasing the ocean model resolution to the eddy resolving level, subsurface warm bias in the subtropical gyres can be reduced (Griffies et al., 2015; Rackow et al., 2019). Besides, ocean simulations are very sensitive to the parameterizations 
representing the oceanic vertical turbulent mixing. For example, an overestimated vertical mixing by strong vertical shear is responsible for the subsurface warm bias in the tropical Indian Ocean (Chowdary et al., 2016), and a salty and warm bias in Antarctic Intermediate Water simulations is largely caused by the misrepresentation of oceanic mixing processes (Zhu et al., 2018).

Based on the previous studies, we will continue to investigate the subsurface temperature bias in the TNP, focusing mainly on the bias contributions from the atmospheric wind forcing fields and the oceanic vertical mixing parameterization by performing CMIP-based analyses and ocean model-based experiments. This paper is organized as follows. Section 2 describes the datasets from CMIP simulations, reanalysis and observational products for model evaluation, and model configurations for MOM5-based numerical experiments. Section 3 describes the characteristics of subsurface temperature biases in the TNP. Atmospheric and oceanic origins of the subsurface temperature biases are investigated in Section 4 and Section 5, respectively. The influences of the temperature biases on the upper-ocean thermal and current structures are discussed in Section 6. Finally, summaries and discussions are given in Section 7.

\section{Datasets and ocean model used}

This study is primarily based on the historical simulations from 53 
CMIP6 models (Eyring et al., 2016), which are available online at https://esgf-node.llnl.gov/projects/cmip6/. The historical simulations are forced by the observed greenhouse gases, solar forcing, and volcanic aerosols from 1850-2014, providing an opportunity to evaluate model abilities to simulate the past climate. In our analysis, the last 35 years (1980-2014) of historical simulations are selected for model evaluations. All the selected CMIP6 outputs are interpolated onto a $1^{\circ}$ horizontal grid, and the potential temperature fields are further interpolated to 87 standard levels with a vertical resolution of $10 \mathrm{~m}$ near the sea surface. As we are interested in the long-term mean biases in climate simulations, the mean states for all fields are calculated by averaging the entire selected period. In addition, 41 CMIP5 models and 16 Ocean Model Intercomparison Project (OMIP) (Griffies et al., 2016) models are also used in our study. All the models are listed in Table 1.

In order to evaluate the subsurface temperature biases in CMIP6 simulations, the EN4 objective analyses of subsurface temperature from the Met Office Hadley Centre are used (Good et al., 2013). The EN4 product consists of temperature and salinity fields from 1900 to the present, with a $1^{\circ}$ horizontal resolution and 42 vertical levels. In addition, wind stress fields are taken from the fifth generation of ECMWF atmospheric reanalyses (ERA5; Copernicus Climate Change Service, 2017) and the Scatterometer Climatology of Ocean Winds (SCOW); the latter is 
estimated from the 122-month record of the QuikSCAT wind measurements (Risien and Chelton, 2008).

Bias quantification is made by conducting the MOM5-based oceanonly experiments (Griffies et al., 2009). This ocean model has a $1^{\circ}$ horizontal resolution with the meridional resolution increased to $1 / 3$ near the equator, and 50 vertical levels with $10 \mathrm{~m}$ resolution in the upper $220 \mathrm{~m}$. In order to investigate the relationship between the subsurface temperature bias in the TNP and the poorly prescribed atmospheric forcing fields, two ocean-only simulations are conducted. In the control run (the LY09 run), the Normal Year atmospheric forcing fields from Large and Yeager (2009), which are the required forcing fields by OMIP (Eyring et al., 2016), is applied. While in the sensitivity run (the ERA5 run), forcing field of wind is replaced by ERA5. Furthermore, in order to investigate the relationship between the subsurface temperature bias in the TNP and the parameterized oceanic vertical mixing processes, several ocean-only experiments are conducted, in which mixing strength in the upper ocean and the interior ocean is reduced. Specifically, the upper boundary layer mixing is modified by reducing the wind stirring effect in a Kraus-Turner type mixing scheme (Chen et al., 1994), and the interior mixing is constrained by using the Argo-derived diffusivity (Zhu and Zhang, 2018a), whose details are given in Section 5. 


\section{Subsurface temperature bias in the TNP}

In the northeastern tropical Pacific (NETP), a subsurface warm bias (SWB) emerges in most of CMIP6 simulations, with its bias center located near $\left(10^{\circ} \mathrm{N}, 130^{\circ} \mathrm{W}\right)$ at the depth of $100 \mathrm{~m}$ (Fig. 1a). The multimodel mean bias is about $4{ }^{\circ} \mathrm{C}$ with the maximum greater than $8{ }^{\circ} \mathrm{C}$ (Fig. 1b). Although great efforts have been made to improve climate model performances over the past decade, the SWB in the NETP has not been reduced significantly from CMIP5 to CMIP6 (Fig. 2). Figure 3 shows the seasonal variation of the SWB. Warm bias is large during April-June, and is relatively small during boreal winter, accompanied by a deep thermocline bias throughout the year.

This SWB is located in an important region where a positive wind stress curl (WSC) produces a positive Ekman pumping near the Intertropical Convergence Zone (ITCZ). As a consequence, a ridge-like climatological thermocline arises to form a potential vorticity barrier blocking the local water exchange between the subtropics and tropics ( $\mathrm{Lu}$ and McCreary, 1995; Johnson and McPhaden, 1999). Therefore, WSC over the NETP might be underestimated by CMIP6 models, and the consequent Ekman upwelling is too weak to maintain the shallow thermocline as observed. In the next section, the relationship between the SWB and the wind stress simulations is examined. 


\section{The contribution of surface wind stress to SWB}

Figure 4a shows the linear regression of the intermodel WSC onto the normalized SWB series (Fig. 1b). The NETP happens to be the region where negative regression coefficients arise. As the weak WSC tends to produce a weak Ekman upwelling, intermodel differences in SWB are largely explained by the differences in the simulation of local WSC. However, whether the WSC intensity in the NETP is underestimated by CMIP6 models is quite uncertain. Figure $4 b$ shows the annual-mean WSC difference between the CMIP6 multimodel ensemble (MME) and the ERA5. It seems plausible that the WSC intensity in the NETP is indeed underestimated by CMIP6 models when the wind fields in ERA5 are considered to be realistic. But it is widely accepted that wind measurements by QuikSCAT are more reliable, and so the QuikSCAT winds are widely used to correct the atmospheric reanalyses winds (Large and Yeager, 2009; Tsujino et al., 2018). Figure 4c shows the WSC difference between the CMIP6 MME and the SCOW. It is obvious that the positive WSC difference extends farther south, almost occupying the entire $10^{\circ} \mathrm{N}$. Hence, the WSC bias in the NETP is positive rather than negative when the QuikSCAT measurements are considered to be more realistic than ERA5. However, the reliability of the QuikSCAT measurements has been questioned. Many previous studies have found that the accuracy of the QuikSCAT measurements can be degraded by rain (Weissman et al., 2002; 
Draper and Long, 2004; Sun et al., 2019). Therefore, the WSC in the ITCZ region can be poorly measured by the QuikSCAT, and correcting the reanalysis winds towards the QuikSCAT winds might introduce a large error. Nevertheless, the forcing fields of wind in OMIP experiments just come from the NCEP and JRA55 wind fields corrected by the QuikSCAT measurements (Griffies et al., 2016). Thus, it is not surprising that this SWB also exists in the OMIP simulations (Fig. 5). To further investigate the relationship between the SWB and the wind forcing fields, two MOM5based ocean-only experiments are conducted. In the LY09 run, the prescribed wind forcing fields are the same as those in the OMIP experiments. In the ERA5 run, ERA5 analysis winds are used to drive the ocean model. Both runs are integrated for 30 years and the outputs for the last 5-year are chosen to calculate the mean state. Figure 6 shows the temperature differences between the ERA5 run and the LY09 run. Compared with that in the LY09 run (Fig. 6a), the SWB is greatly reduced by $\sim 6^{\circ} \mathrm{C}$ in the ERA5 run (Fig. $6 \mathrm{c}$ ), implying that the failure of reproducing the subsurface temperature distribution in the tropical North Pacific is due to the poorly prescribed wind forcing fields in OMIP experiments.

Although the above analyses confirm a significant contribution of the wind stress simulations to the SWB in the NETP, its quantitative contribution is still unknown as it is difficult to obtain the accurate wind measurements and to realistically describe the WSC distributions in the 
254

255

256

\section{7}

tropics for ocean modeling. Here, we further discuss the possible mechanisms impacting the wind simulations in the NETP. As shown in Figure 7, the SWB is closely related to the northeasterly wind in the NETP, which helps to produce a negative WSC on its right flank (Fig. 4a). Song and Zhang (2020) have found that the climate models fail to reproduce the seasonal wind reversal of the North American monsoon, leading to a yearround northeasterly wind bias in the NETP. Consistent with their study, Figure 7 shows positive regression coefficients between the sea level pressure and the SWB over the North America. Thus, the overestimated sea level pressure over the North America acts to produce a year-round northeasterly wind bias in the NETP, which further causes a negative WSC bias on its right flank. This negative WSC bias acts to suppress the local Ekman upwelling, leading to the emergence of the SWB in the NETP as represented in the CMIP simulations.

\section{The contribution of oceanic vertical mixing scheme to SWB}

Apart from the erroneous simulations in atmospheric state, the deficiencies in ocean models can also contribute to the SWB in the NETP. One of the largest sources of errors in ocean models is the parameterizations of the vertical turbulent mixing processes in the upper ocean, and the ocean simulations are very sensitive to the vertical diffusivity estimated by vertical mixing schemes. Over the past two 
decades, three microstructure observations (Thurnherr and Laurent, 2011;

277 Cheng and Kitade, 2014; Fernández-Castro et al., 2014) are conducted in 278 the NETP (Fig. 8), providing an opportunity to assess the ability of vertical 279 mixing schemes in reproducing the observed mixing strength. Different 280 from what is observed, the estimated vertical diffusivity in ocean models 281 is misrepresented in the vertical: In the ocean boundary layer, the intense 282 vertical mixing penetrates too deep, and in the ocean interior, vertical 283 diffusivity is overestimated by an order of magnitude (Fig. 9, see also the 284 285 (2014)).

The overly strong penetration of the ocean boundary layer mixing tends to warm the subsurface layer. Thus, sensitivity experiments are conducted to investigate the relationship between the SWB in NETP and 289 the overly strong mixing effect. In this subsection, a Kraus-Turner-type vertical mixing scheme (Niiler, 1977; Chen et al., 1994) is applied to 291 determine the mixed layer depth as follows:

$292 \Delta b w_{e} h=2 m_{0} u_{*}^{3}+\frac{\left[(1+n) B_{0}-(1-n)\left|B_{0}\right|\right] h}{2}+J_{0}\left[h\left(1+e^{-h / h_{p}}\right)-2 h_{p}\left(1-e^{-h / h_{p}}\right)\right]$

where $\Delta b$ is the buoyancy jump across the base of ocean surface 294 boundary layer, $w_{e}=\partial h / \partial t$ is the entrainment velocity, $h$ is the depth of 295 ocean surface boundary layer, $u_{*}$ is the friction velocity, $B_{0}$ and $J_{0}$ are the non-penetrating and penetrating components of the surface buoyancy flux, and $h_{p}$ is the attenuation depth of shortwave radiation in the upper ocean. 
Here, $m_{0}$ is a parameter to scale the wind stirring effect; $n$ is a parameter to represent the ratio of entrainment buoyancy flux to surface buoyancy flux when convection occurs. Traditionally, constant values with $m_{0}=0.4$ and $n=0.18$ are taken in ocean modelling, but some previous studies find that $m_{0}$ is spatially varying with values less than 0.4 in the NETP (Acreman and Jeffery, 2007; Zhu and Zhang, 2018a). This prognostic equation of $h$ has been employed into MOM5 to depict the evolution of ocean surface boundary layer. When the $h$ is determined by the equation (1), vertical mixing coefficients for the model layers within the $h$ are assigned to be a constant value of $5 \times 10^{-3} \mathrm{~m}^{2} \mathrm{~s}^{-1}$, the maximum observed diffusivity reported by Peters et al. (1988). Thus, the overly deep penetration of boundary layer mixing demonstrated in Figure 9 can be relieved by reducing the $m_{0}$ in the equation (1). Two MOM5 based ocean-only simulations are thus conducted: $m_{0}=0.4$ is taken in the control run; in the reduced $m_{0}$ run, the $m_{0}$ is prescribed as

$$
0.4 \times\left(1-\exp \left(-\left(\frac{l o n-130^{\circ} W}{20^{\circ}}\right)^{2}\right) \cdot \exp \left(-\left(\frac{l a t-11^{\circ} N}{4^{\circ}}\right)^{2}\right)\right)
$$

in which "lon" and "lat" are the longitude and latitude of a model grid point. Both runs are integrated for 30 years using the atmospheric climatological forcing fields from LY09, and the outputs for the last 5 years are selected for comparisons.

Figure 10a shows the annual-mean difference in ocean surface boundary layer depth between the reduced $m_{0}$ run and the control run. In 
accord with equation (2), surface boundary layer shoals by $\sim 15 \mathrm{~m}$ in the NETP when the $m_{0}$ is reduced, roughly removing the too deep surface boundary layer depth bias in Figure 9b. As a consequence, subsurface layer cools by $\sim 1{ }^{\circ} \mathrm{C}$ in the NETP (Fig. 10b). Moreover, the SWB is found to be more pronounced during the first half of a year (Fig. 6b). By reducing the penetration depth of the boundary layer mixing, improvements in the subsurface temperature simulations are much substantial in the reduced $m_{0}$ run during the first half of a year (Fig. 10c), revealing that the overly strong penetration of the mixing effect and the ocean surface boundary layer deepening indeed contribute to the SWB in the NETP.

Besides the misrepresented boundary layer mixing, the overestimated vertical mixing in the ocean interior may also contribute to the SWB in the NETP by inhibiting the downward heat transport to the deeper ocean. Indeed, the spatial pattern of diapycnal mixing in the tropical Pacific inferred from the strain-based finescale parameterization (Kunze et al., 2006) also confirms the weak mixing strength in the NETP for observations, coinciding with the location of the SWB (Fig. 11a). Thus similar to our previous studies (Zhu and Zhang, 2018a; Zhu et al., 2020b), two oceanonly experiments are conducted to investigate the relationship between the SWB and diapycnal mixing intensity in the NETP. In the control run, background diffusivity is taken as the commonly used value $\left(10^{-5} \mathrm{~m}^{2} \mathrm{~s}^{-1}\right)$, a value that is considered to be too large compared to what is observed. In 
the reduced background diffusivity (RBD) run considering the observed weak diapycnal mixing, background diffusivity over the NETP is replaced by the Argo-derived one (Fig. 11a). Two runs are integrated for 30 years using the LY09 forcing fields. The temperature differences averaged over the last 5 years are shown in Figure $11 \mathrm{~b}$ and $11 \mathrm{c}$, revealing that the SWB can be reduced when constraining the background diffusivity to match what is observed.

So, our modeling experiments clearly demonstrate that the uncertainties in the oceanic vertical mixing parameterization can produce $\mathrm{a} \sim 3{ }^{\circ} \mathrm{C}$ warm bias, and the poorly simulated wind stress fields (Fig. 6c) can cause a $\sim 6{ }^{\circ} \mathrm{C}$ warm bias. Putting together, these two effects could account for the magnitude of SWB in coupled simulations. Although this warm bias occupies a small domain of the tropical Pacific basin, its influences might be widespread as the upper-ocean thermal structures in the TNP control the subtropical-tropical water exchanges. In the next section, some local and remote consequences of the SWB are further discussed.

\section{The consequences of the SWB}

In order to investigate the relationships between the SWB and the simulated oceanic circulations pathways in CMIP6 outputs, we define two model groups according to the magnitude of SWB (Fig. 12a): 14 models 
are seen to have large SWB (Group1), and 10 models are seen to have trivial or little SWB (Group2). As shown in Figure 12b-12d, the CMIP6 models with a large SWB in the NETP tend to produce much flatter isopycnals over the central TNP, which acts to reduce interior water transport. As a consequence, the equatorward water transport at 50-150 m in the western-central TNP is weaker than that in the models with a small SWB. Furthermore, the equatorward water transport in the subsurface TNP regulates the supply of cold water that upwells along the equator, which can be associated with the decadal changes in SST over the central and eastern equatorial Pacific (McPhaden and Zhang, 2002; Capotondi et al., 2005). Figure $13 \mathrm{a}$ and $13 \mathrm{~b}$ contrast the equatorial Pacific upwelling simulated in Group1 and Group2. Consistent with our understanding of subtropical-tropical water exchange, models with the large SWB tend to produce a weak equatorial upwelling (Fig. 13c). Thus, the cooling effect by the equatorial upwelling in Group1 is weak, and the upper-ocean temperature difference between Group1 and Group2 is positive (Fig. 14a). Figure $14 \mathrm{~b}$ shows the scatterplots of the SWB versus the equatorial Pacific upper-ocean temperature among the 53 CMIP6 models. Obviously, these two quantities show a positive correlation $(\mathrm{R}=0.75)$, indicating that the CMIP6 models with the larger SWB in the NETP tend to produce a warmer equatorial upper-ocean. 


\section{Summary and discussion}

Thermal structure and variability in the subsurface oceans are known to play an important role in the climate change, and the studies of oceanic subsurface temperature biases are important for understanding the simulations and predictions of global energy and heat redistribution. Though being substantial in climate simulations, subsurface biases have not been received much attention yet. In this study, subsurface temperature biases in the TNP are investigated using the newly released CMIP6 historical simulations. It is found that almost all the CMIP6 simulations have a pronounced SWB that is persistent throughout the year in the NETP, and the model updates from CMIP5 to CMIP6 do not provide obvious bias alleviations for temperature biases. The SWB is primarily caused by the model deficiencies in simulating the surface WSC. For a similar reason, the poorly prescribed wind forcing also causes a pronounced SWB in the NETP in OMIP simulations. Besides, this SWB can also be partly attributed to the uncertainties in the representations of the oceanic vertical mixing processes. Compared with the observations, the estimated vertical diffusivity in ocean model is misrepresented in both the upper boundary layer and the ocean interior. By constraining the diffusivity to match observations, SWB in the NETP is reduced by $\sim 3{ }^{\circ} \mathrm{C}$. The consequence of the SWB in the NETP is further examined using the CMIP6 products. The SWB can influence the simulations of oceanic circulations and equatorial 
upper-ocean thermal structure. The CMIP6 simulations with a large SWB tend to produce a weak equatorward water transport in the subsurface TNP, a weak equatorial upwelling and thus a warm upper ocean layer along the equator.

Substantial subsurface temperature biases are also seen in other regions of the world ocean (Fig. 15a). Unfortunately, it seems that no substantial improvements are achieved from CMIP5 to CMIP6 (Fig. 15b), and much more efforts are needed to understand the sources of subsurface biases and ultimately to remove them. It is interesting to note that the subsurface temperature bias is often accompanied by a bias in salinity simulation, and the biases in temperature and salinity are compensated for by each other in terms of their effects on density. For example, the large subsurface cold bias centered at (the Pacific sector, $8^{\circ} \mathrm{S}, 200 \mathrm{~m}$ ) is accompanied by a fresh bias. Because these two biases tend to be compensated for by each other in terms of their effects on density, density bias is reduced. Compensation of temperature and salinity is a property commonly observed in water masses (Lilly et al., 1999; Rudnick and Ferrari, 1999). Thus, subsurface thermohaline biases might be closely related to the water mass formation and transformation in the global oceans. Figure 14 shows a positive correlation between the SWB and the equatorial upper-ocean temperature in CMIP6 models. Previous studies have found that the cold bias in the upper tropical Pacific Ocean affects the 
ENSO simulations in climate models, leading to an intermodel diversity of ENSO representations in CMIP5 simulations (Vannière et al., 2013; Kim et al., 2014). The upper ocean temperature bias in the equatorial Pacific is a possible cause of forecast errors in ENSO amplitude (Kim et al., 2017). Thus, the SWB might be linked to the ENSO simulations in climate models, and further research efforts are needed to test this hypothesis.

\section{Acknowledgement.}

We thank Andreas M. Thurnherr at Lamont-Doherty Earth Observatory for providing the LADDER data. We acknowledge the World Climate Research Programme, which, through its Working Group on Coupled Modelling, coordinated and promoted CMIP6. We thank the climate modeling groups for producing and making available their model output, the Earth System Grid Federation (ESGF) for archiving the data and providing access, and the multiple funding agencies who support CMIP6 and ESGF. This research is supported by the National Natural Science Foundation of China (Grant Nos. 41906007, 41690122(41690120), 42030410, 41705082, 41421005), the National Key Research and Development Program of China (No. 2017YFC1404102(2017YFC1404100)), the Strategic Priority Research Program of Chinese Academy of Sciences (Grant Nos. XDB 40000000 and XDB 42000000), and the Shandong Taishan Scholarship. 


\section{References}

454 Acreman, D. M., and C. D. Jeffery, 2007: The use of Argo for validation and tuning of mixed layer models. Ocean Modell., 19, 53-69.

456

457

458

459

460

461

462

463

464

465

466

467

468

469

470

471

472

473

Burls, N. J., L. Muir, E. M. Vincent, and A. Fedorov, 2017: Extra-tropical origin of equatorial Pacific cold bias in climate models with links to cloud albedo. Clim. Dyn., 49, 2093-2113.

Capotondi, A., M. A. Alexander, C. Deser, and M. J. McPhaden, 2005: Anatomy and Decadal Evolution of the Pacific Subtropical-Tropical Cells (STCs)*. J. Climate, 18, 3739-3758.

Chen, D., L. M. Rothstein, and A. J. Busalacchi, 1994: A Hybrid Vertical Mixing Scheme and Its Application to Tropical Ocean Models. J. Phys. Oceanogr., 24, 2156-2179.

Chen, X. Y., and K. K. Tung, 2014: Varying planetary heat sink led to global-warming slowdown and acceleration. Science, 345, 897-903.

Cheng, L., and Y. Kitade, 2014: Quantitative evaluation of turbulent mixing in the Central Equatorial Pacific. J. Oceanogr., 70, 63-79.

Chowdary, J. S., A. Parekh, G. Srinivas, C. Gnanaseelan, T. S. Fousiya, R. Khandekar, and M. K. Roxy, 2016: Processes Associated with the Tropical Indian Ocean Subsurface Temperature Bias in a Coupled Model. J. Phys. Oceanogr., 46, 2863-2875.

Copernicus Climate Change Service (C3S), 2017: ERA5: Fifth generation 
of ECMWF atmospheric reanalyses of the global climate. Copernicus Climate Change Service Climate Data Store (CDS), 2019/04/24. $\underline{\text { https://cds.climate.copernicus.eu/cdsapp\#!/home. }}$

477

478

479

480

481

482

483

484

485

486

487

488

489

490

491

492

493

494

495

Draper, D. W., and D. G. Long, 2004: Evaluating the effect of rain on SeaWinds scatterometer measurements. J. Geophys. Res., 109, C02005.

Eyring, V., S. Bony, G. A. Meehl, C. A. Senior, B. Stevens, R. J. Stouffer, and K. E. Taylor, 2016: Overview of the Coupled Model Intercomparison Project Phase 6 (CMIP6) experimental design and organization. Geosci. Model Dev., 9, 1937-1958.

Fernández-Castro, B., and Coauthors, 2014: Microstructure turbulence and diffusivity parameterization in the tropical and subtropical Atlantic, Pacific and Indian Oceans during the Malaspina 2010 expedition. Deep Sea Research Part I: Oceanographic Research Papers, 94, 1530.

Furue, R., and Coauthors, 2015: Impacts of regional mixing on the temperature structure of the equatorial Pacific Ocean. Part 1: Vertically uniform vertical diffusion. Ocean Modell., 91, 91-111.

Gao, C., and R.-H. Zhang, 2017: The roles of atmospheric wind and entrained water temperature (Te) in the second-year cooling of the 2010-12 La Niña event. Clim. Dyn., 48, 597-617.

Good, S. A., M. J. Martin, and N. A. Rayner, 2013: EN4: Quality controlled 
ocean temperature and salinity profiles and monthly objective analyses with uncertainty estimates. J. Geophys. Res., 118, 6704-6716.

498 Gordon, C. T., A. Rosati, and R. Gudgel, 2000: Tropical Sensitivity of a Coupled Model to Specified ISCCP Low Clouds. J. Climate, 13, 2239-2260.

Griffies, S. M., and Coauthors, 2009: Coordinated Ocean-ice Reference Experiments (COREs). Ocean Modell., 26, 1-46.

Griffies, S. M., and Coauthors, 2015: Impacts on Ocean Heat from Transient Mesoscale Eddies in a Hierarchy of Climate Models. $J$. Climate, 28, 952-977.

Griffies, S. M., and Coauthors, 2016: OMIP contribution to CMIP6: experimental and diagnostic protocol for the physical component of the Ocean Model Intercomparison Project. Geosci. Model Dev., 9, 3231-3296.

Guilyardi, E., and Coauthors, 2009: Understanding El Niño in OceanAtmosphere General Circulation Models: Progress and Challenges. Bull. Amer. Meteor. Soc., 90, 325-340.

Jia, Y. L., R. Furue, and J. P. McCreary, 2015: Impacts of regional mixing on the temperature structure of the equatorial Pacific Ocean. Part 2: Depth-dependent vertical diffusion. Ocean Modell., 91, 112-127. Jochum, M., 2009: Impact of latitudinal variations in vertical diffusivity on climate simulations. J. Geophys. Res., 114, C01010. 
Johnson, G. C., and M. J. McPhaden, 1999: Interior Pycnocline Flow from the Subtropical to the Equatorial Pacific Ocean. J. Phys. Oceanogr., 29, 3073-3089.

Kim, S. T., H.-I. Jeong, and F.-F. Jin, 2017: Mean Bias in Seasonal Forecast Model and ENSO Prediction Error. Sci. Rep., 7, 6029.

Kim, S. T., W. Cai, F.-F. Jin, and J.-Y. Yu, 2014: ENSO stability in coupled climate models and its association with mean state. Clim. Dyn., 42, 3313-3321.

Kunze, E., E. Firing, J. M. Hummon, T. K. Chereskin, and A. M. Thurnherr, 2006: Global Abyssal Mixing Inferred from Lowered ADCP Shear and CTD Strain Profiles. J. Phys. Oceanogr., 36, 1553-1576.

Large, W. G., and S. G. Yeager, 2009: The global climatology of an interannually varying air-sea flux data set. Clim. Dyn., 33, 341-364.

Li, G., S.-P. Xie, Y. Du, and Y. Luo, 2016: Effects of excessive equatorial cold tongue bias on the projections of tropical Pacific climate change. Part I: the warming pattern in CMIP5 multi-model ensemble. Clim. Dyn., 47, 3817-3831.

Lilly, J. M., P. B. Rhines, M. Visbeck, R. Davis, J. R. N. Lazier, F. Schott, and D. Farmer, 1999: Observing Deep Convection in the Labrador Sea during Winter 1994/95 \%J Journal of Physical Oceanography. $J$. Phys. Oceanogr., 29, 2065-2098.

Lu, P., and J. P. McCreary, 1995: Influence of the ITCZ on the Flow of 
Thermocline Water from the Subtropical to the Equatorial Pacific Ocean. J. Phys. Oceanogr., 25, 3076-3088.

Ma, C.-C., C. R. Mechoso, A. W. Robertson, and A. Arakawa, 1996: 
Rudnick, D. L., and R. Ferrari, 1999: Compensation of Horizontal Temperature and Salinity Gradients in the Ocean Mixed Layer. Science, 283, 526-529.

Sasaki, W., K. J. Richards, and J. J. Luo, 2013: Impact of vertical mixing induced by small vertical scale structures above and within the equatorial thermocline on the tropical Pacific in a CGCM. Clim. Dyn., 41, 443-453.

Seo, H., M. Jochum, R. Murtugudde, and A. J. Miller, 2006: Effect of ocean mesoscale variability on the mean state of tropical Atlantic climate. Geophys. Res. Lett., 33, L09606.

Small, R. J., and Coauthors, 2014: A new synoptic scale resolving global climate simulation using the Community Earth System Model. J. $A d v$. Model. Earth Syst., 6, 1065-1094.

Song, F., and G. J. Zhang, 2020: The Impacts of Horizontal Resolution on the Seasonally Dependent Biases of the Northeastern Pacific ITCZ in Coupled Climate Models. J. Climate, 33, 941-957.

Sun, Z., H. Liu, P. Lin, Y.-h. Tseng, J. Small, and F. Bryan, 2019: The Modeling of the North Equatorial Countercurrent in the Community Earth System Model and its Oceanic Component. Journal of Advances in Modeling Earth Systems, 11, 531-544.

Thomas, M. D., and A. V. Fedorov, 2017: The Eastern Subtropical Pacific Origin of the Equatorial Cold Bias in Climate Models: A Lagrangian 
Perspective. J. Climate, 30, 5885-5900.

Tsujino, H., and Coauthors, 2018: JRA-55 based surface dataset for driving ocean-sea-ice models (JRA55-do). Ocean Modell., 130, 79-139.

Vannière, B., E. Guilyardi, G. Madec, F. J. Doblas-Reyes, and S. Woolnough, 2013: Using seasonal hindcasts to understand the origin of the equatorial cold tongue bias in CGCMs and its impact on ENSO. Clim. Dyn., 40, 963-981.

Wang, G., L. Cheng, J. Abraham, and C. Li, 2018: Consensuses and discrepancies of basin-scale ocean heat content changes in different ocean analyses. Clim. Dyn., 50, 2471-2487.

Weissman, D. E., M. A. Bourassa, and J. Tongue, 2002: Effects of Rain Rate and Wind Magnitude on SeaWinds Scatterometer Wind Speed Errors. J. Atmos. Oceanic Technol., 19, 738-746.

Wittenberg, A. T., A. Rosati, N.-C. Lau, and J. J. Ploshay, 2006: GFDL's CM2 Global Coupled Climate Models. Part III: Tropical Pacific Climate and ENSO. J. Climate, 19, 698-722.

Woelfle, M. D., S. Yu, C. S. Bretherton, and M. S. Pritchard, 2018: Sensitivity of Coupled Tropical Pacific Model Biases to Convective Parameterization in CESM1. J. Adv. Model. Earth Syst., 10, 126-144. Xu, Z., M. Li, C. M. Patricola, and P. Chang, 2014: Oceanic origin of southeast tropical Atlantic biases. Clim. Dyn., 43, 2915-2930.

Ying, J., P. Huang, T. Lian, and H. Tan, 2019: Understanding the effect of 

an excessive cold tongue bias on projecting the tropical Pacific SST warming pattern in CMIP5 models. Clim. Dyn., 52, 1805-1818.

Zhang, R.-H., and Coauthors, 2020: A review of progress in coupled oceanatmosphere model developments for ENSO studies in China. Journal of Oceanology and Limnology, 38, 930-961.

Zhu, C., Z. Liu, and S. Gu, 2018: Model bias for South Atlantic Antarctic intermediate water in CMIP5. Clim. Dyn., 50, 3613-3624.

Zhu, Y., and R.-H. Zhang, 2018a: Scaling wind stirring effects in an oceanic bulk mixed layer model with application to an OGCM of the tropical Pacific. Clim. Dyn., 51, 1927-1946.

Zhu, Y., and R.-H. Zhang, 2018b: An Argo-Derived Background Diffusivity Parameterization for Improved Ocean Simulations in the Tropical Pacific. Geophys. Res. Lett., 45, 1509-1517.

Zhu, Y., and R.-H. Zhang, 2019: A Modified Vertical Mixing Parameterization for Its Improved Ocean and Coupled Simulations in the Tropical Pacific. J. Phys. Oceanogr., 49, 21-37.

Zhu, Y., R.-H. Zhang, and J. Sun, 2020a: North Pacific Upper-Ocean Cold Temperature Biases in CMIP6 Simulations and the Role of Regional Vertical Mixing. J. Climate, 33, 7523-7538.

Zhu, Y., R.-H. Zhang, D. Li, and D. Chen, 2020b: The thermocline biases in the tropical North Pacific and their attributions. J. Climate, 1-17. Retrieved Dec 15 , 2020 , from 
628 https://journals.ametsoc.org/view/journals/clim/aop/JCLI-D-20-

$629 \quad$ 0675.1/JCLI-D-20-0675.1.xml

630 
631

632

633

634

635

636 Development

Program

637

638

639

640

641

642

643

644

645

646

647

\section{Declarations}

\section{Funding}

\section{Availability of data and material}

Not applicable.

\section{Code availability}

This research is supported by the National Natural Science Foundation of China (Grant Nos. 41906007, 41690122(41690120), 42030410, 41705082, 41421005), the National Key Research and 2017YFC1404102(2017YFC1404100)), the Strategic Priority Research Program of Chinese Academy of Sciences (Grant Nos. XDB 40000000 and XDB 42000000), and the Shandong Taishan Scholarship.

\section{Conflicts of interest/Competing interests}

The authors declare no competing interests.

The data and computer codes used in the paper are available from the corresponding author (e-mail: rzhang@qdio.ac.cn). 
648

649

650

651

652

653

654

655

656

657

658

659

660

661

662

663

664

665

666

667

668

669

\section{Legends}

Table 1. CMIP and OMIP models used in this study.

Figure 1. (a) Spatial distributions of multimodel annual mean bias greater than $3{ }^{\circ}$ C. (b) Subsurface temperature bias in the individual CMIP6 models, which is calculated by averaging the temperature bias over the region where the multimodel mean bias is greater than $3{ }^{\circ} \mathrm{C}$. The $\mathrm{x}$-axis denotes the model numbers, which are listed in Table 1.

Figure 2. The same as in Figure 1a but for the subsurface warm bias in CMIP5 multimodel ensemble.

Figure 3. Seasonal variation in the SWB, which is the horizontally averaged over the region $\left(8^{\circ}-15^{\circ} \mathrm{N}, 110^{\circ}-150^{\circ} \mathrm{W}\right)$. The $20^{\circ} \mathrm{C}$ isotherm depth from the EN4 is denoted by the solid line, and that from the CMIP6 MME is denoted as the dashed line.

Figure 4. (a) Linear regression of the inter-model WSC $\left[\mathrm{N} \mathrm{m}^{-3}\right]$ onto the normalized series of SWB (Fig. 1b). The dots denote the region where Pvalue is smaller than 0.05. (b, c) WSC bias relative to ERA5 and SCOW, respectively.

Figure 5. (a) SWB $\left[{ }^{\circ} \mathrm{C}\right]$ at the depth of $100 \mathrm{~m}$ in the OMIP MME. (b) The WSC difference $\left[\mathrm{N} \mathrm{m}^{-3}\right]$ between the OMIP MME and the ERA5.

Figure 6. (a) Temperature bias at the depth of $100 \mathrm{~m}$ and (b) the verticalseason section of temperature bias horizontally averaged over the NETP in the LY09 run. (c, d) The differences between the ERA5 run and the LY09 
670

671 Figure 7. Linear regressions of the intermodel sea level pressure [color, $\mathrm{Pa}$ ]

672 and wind stress vectors $\left[\mathrm{N} \mathrm{m}^{-2}\right]$ onto the normalized SWB.

673 Figure 8. Base-10 logarithm of the vertical diffusivity (the averaged over $\left.674\left(8^{\circ}-15^{\circ} \mathrm{N}, 110^{\circ}-150^{\circ} \mathrm{W}\right), \mathrm{m}^{2} \mathrm{~s}^{-1}\right)$ from the ocean-only experiment. Given 675 the short period of the LY09 forcing fields (1948-2009), another OMIP676 recommended forcing fields (Tsujino et al., 2018) spanning 1958-2018 are 677 used to drive the MOM5. Model outputs for the vertical diffusivity from 678 679 observations are indicated by the black lines.

680 Figure 9. (a) Microstructure profiles from the LADDER project (kindly 681 provided by Professor Andreas M. Thurnherr at Lamont-Doherty Earth 682 683 684 685 686 687 688 689 690 691 2004-2012 are shown in colors, and three in-situ microstructure Observatory). These data were collected in the eastern tropical Pacific near the crest of the East Pacific Rise $\left(9^{\circ} 30^{\prime}-10^{\circ} \mathrm{N}, 103^{\circ} 45^{\prime}-105^{\circ} \mathrm{W}\right)$ using Vertical Microstructure Profiler (VMP) during November to December, 2007. (b) The corresponding vertical diffusivity in MOM5 based oceanonly simulation.

Figure 10. Annual-mean differences in (a) ocean surface boundary layer [m] and (b) temperature at the depth of $100 \mathrm{~m}\left[{ }^{\circ} \mathrm{C}\right]$ between the reduced $m_{0}$ run and the control run. (c) Vertical-season section of temperature difference horizontally averaged over the NETP.

Figure 11. (a) Diapycnal diffusivity estimated based on the finescale 
692 parameterization using the Argo profiles (available online at 693 ftp://ftp.ifremer.fr/ifremer/argo/) with 2-10 m vertical resolution and from 6942006 to 2019. (b, c) The temperature differences between the RBD run and 695 the control run.

696 Figure 12. (a) Two model groups classified in terms of the SWB magnitude. 697 Models in the Group1 have large SWB, while SWB in the Group2 is trivial. 698 (c-d) Meridional velocity differences between the Group1 and Group2 699 [colors, $\left.\mathrm{cm} \mathrm{s}^{-1}\right]$, and potential density $\left[\mathrm{kg} \mathrm{m}^{-3}\right]$ in Group 1 MME (solid lines) 700 and Group2 MME (dashed lines) along $5^{\circ} \mathrm{N}, 10^{\circ} \mathrm{N}$ and $15^{\circ} \mathrm{N}$, respectively.

701

702 703 704 705 706 707 708 709 710

Figure 13. Vertical velocity $\left[\mathrm{m} \mathrm{day}^{-1}\right]$ along the equator in the (a) Group1 MME and (b) Group2 MME. (c) The difference between Group1 and Group2.

Figure 14. (a) Temperature differences $\left[{ }^{\circ} \mathrm{C}\right]$ along the equator between the Group1 and Group2. (b) Scatterplots of the relationship between the SWB and the equatorial Pacific temperature averaged over $\left(0-100 \mathrm{~m}, 140^{\circ} \mathrm{E}-80^{\circ}\right.$ W).

Figure 15. The basinwide zonally averaged biases for temperature (colors) and salinity (contours) biases in (a) CMIP6 and (b) CMIP5. 


\section{Figures}
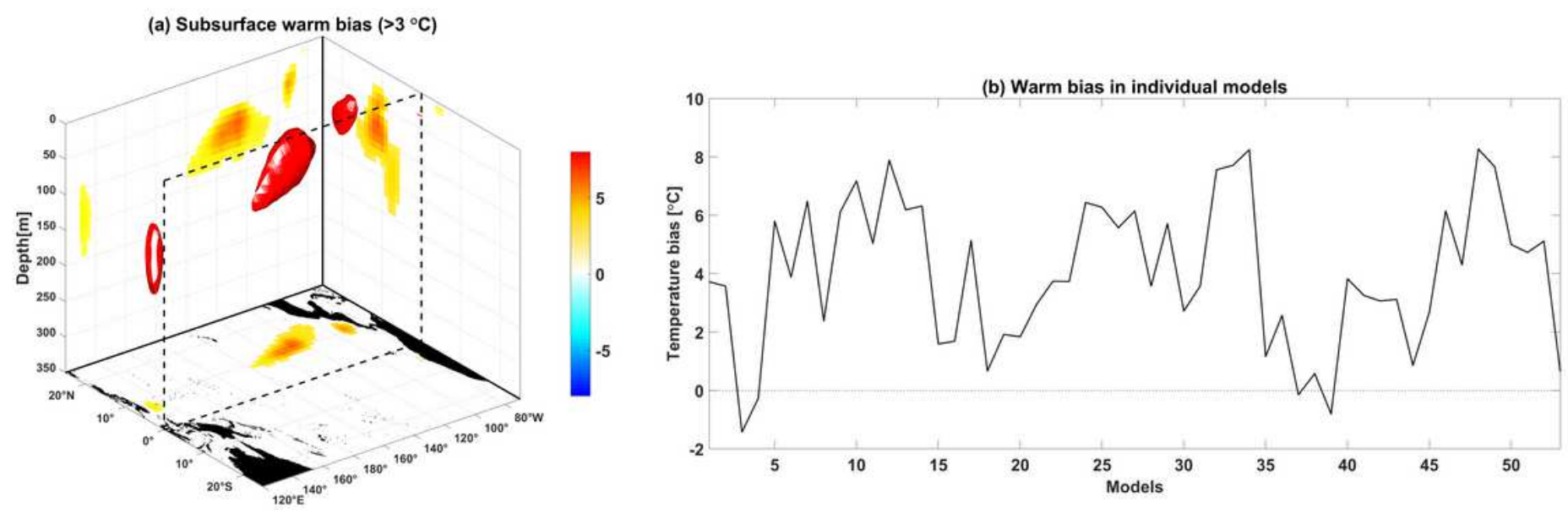

Figure 1

(a) Spatial distributions of multimodel annual mean bias greater than $3{ }^{\circ} \mathrm{C}$. (b) Subsurface temperature bias in the individual CMIP6 models, which is calculated by averaging the temperature bias over the region where the multimodel mean bias is greater than $3^{\circ} \mathrm{C}$. The $\mathrm{x}$-axis denotes the model numbers, which are listed in Table 1. 


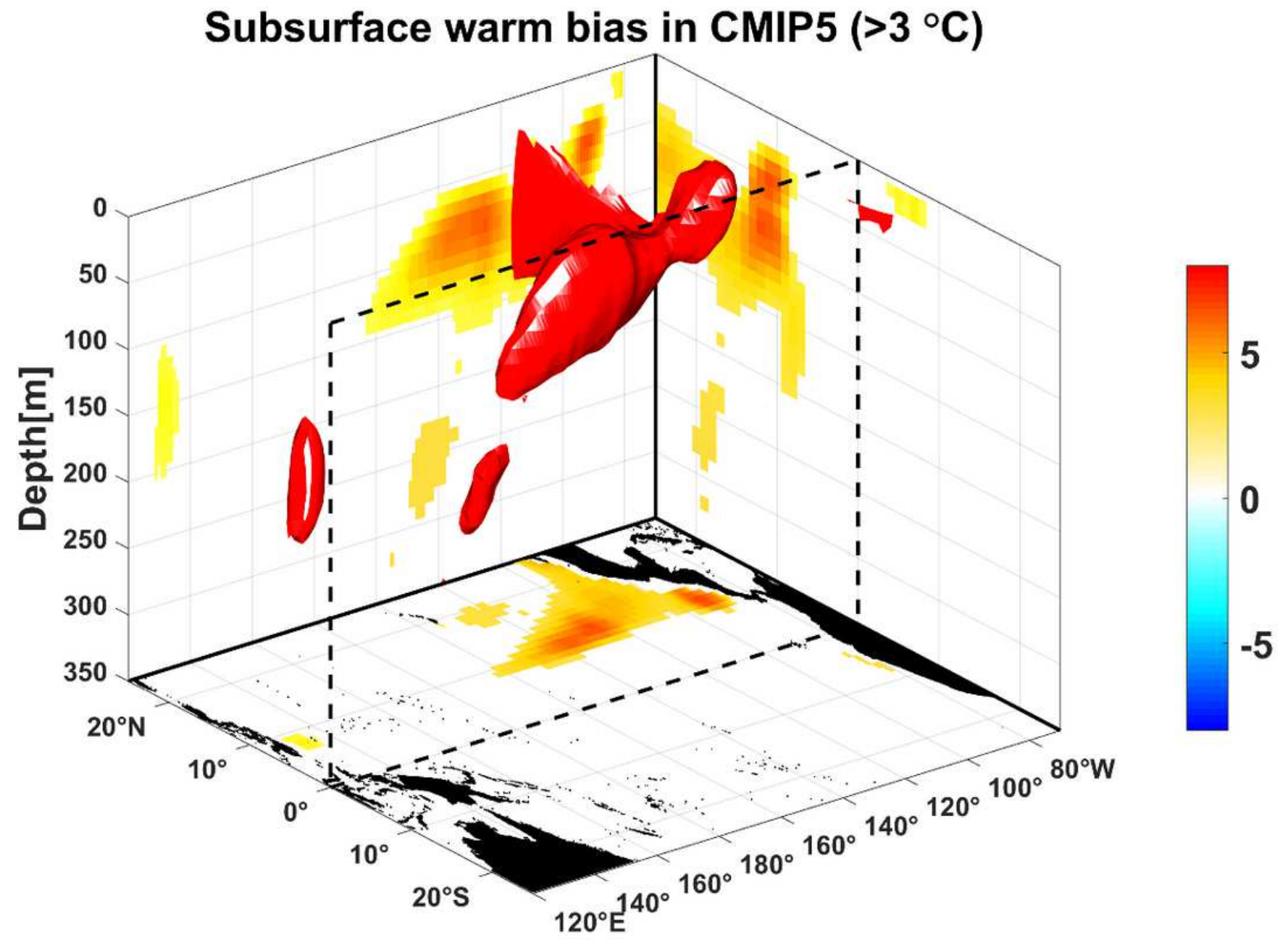

Figure 2

The same as in Figure 1a but for the subsurface warm bias in CMIP5 multimodel ensemble. 


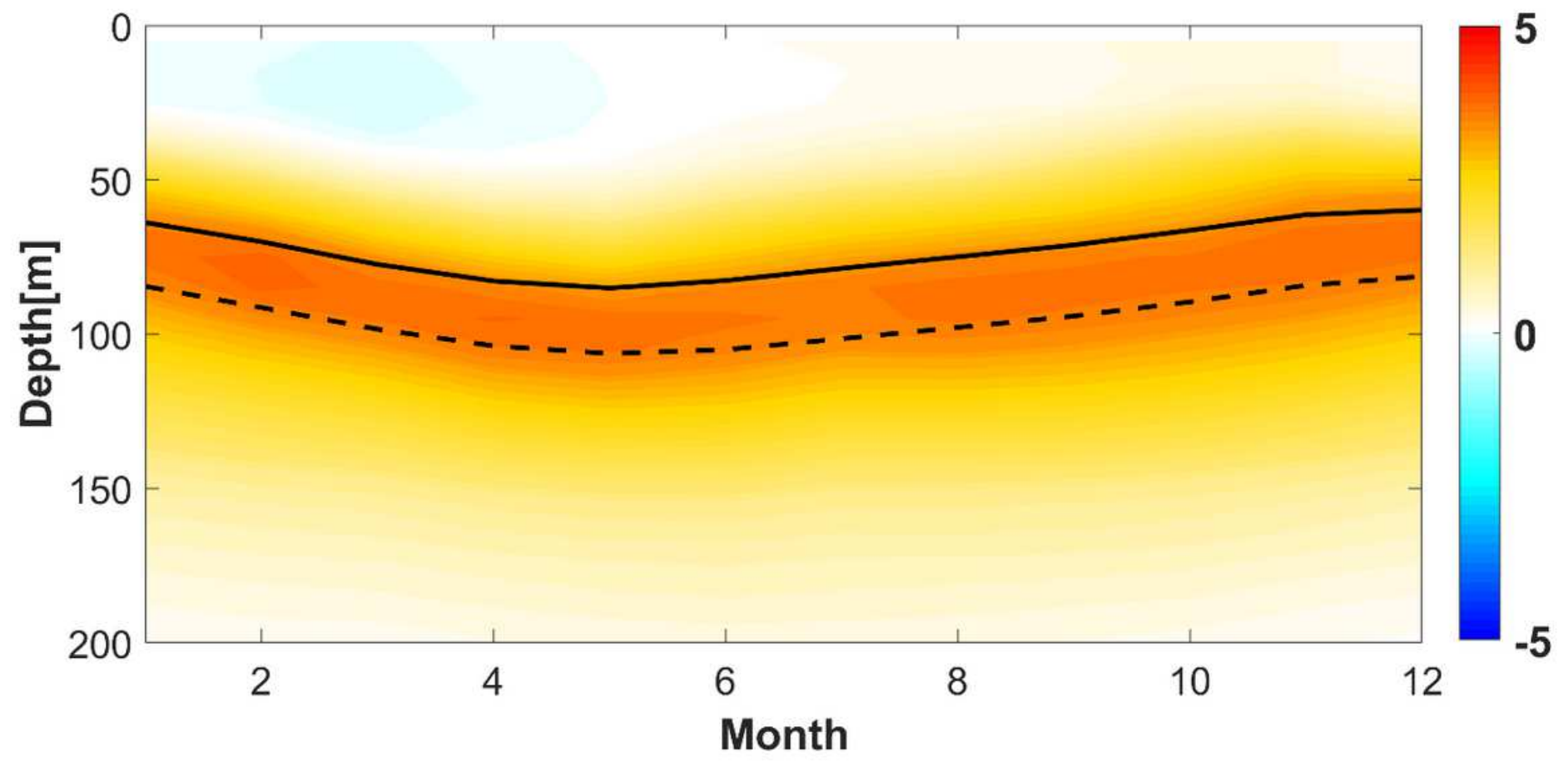

Figure 3

Seasonal variation in the SWB, which is the horizontally averaged over the region $\left(8^{\circ}-15^{\circ} \mathrm{N}, 110^{\circ}-150^{\circ} \mathrm{W}\right)$. The $20^{\circ} \mathrm{C}$ isotherm depth from the EN4 is denoted by the solid line, and that from the CMIP6 MME is denoted as the dashed line. 

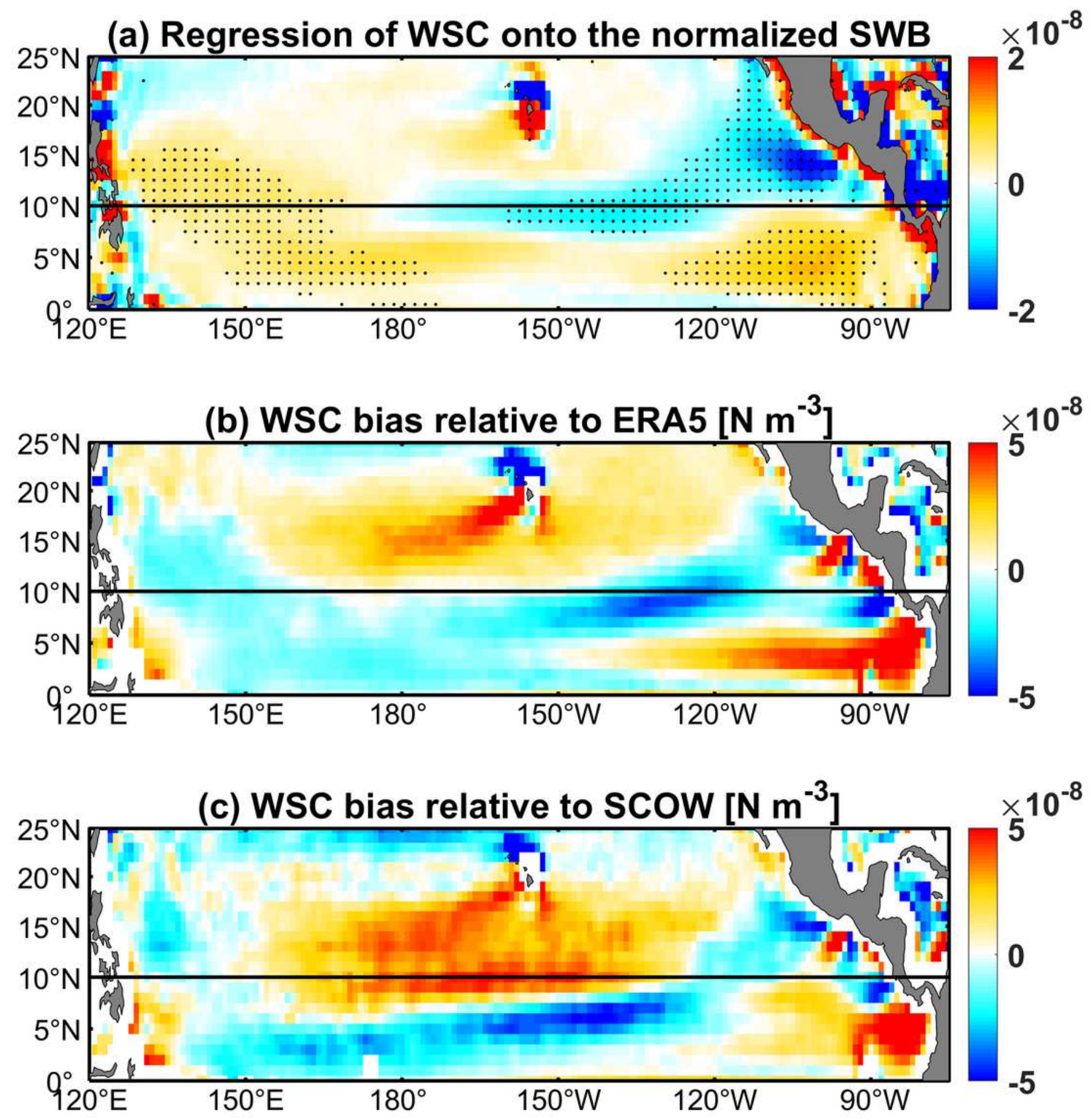

Figure 4

(a) Linear regression of the inter-model WSC [N m-3] onto the normalized series of SWB (Fig. 1b). The dots denote the region where P-value is smaller than 0.05. (b, c) WSC bias relative to ERA5 and SCOW, respectively. 
(a) Temperature bias at $100 \mathrm{~m}$ in OMIP MME

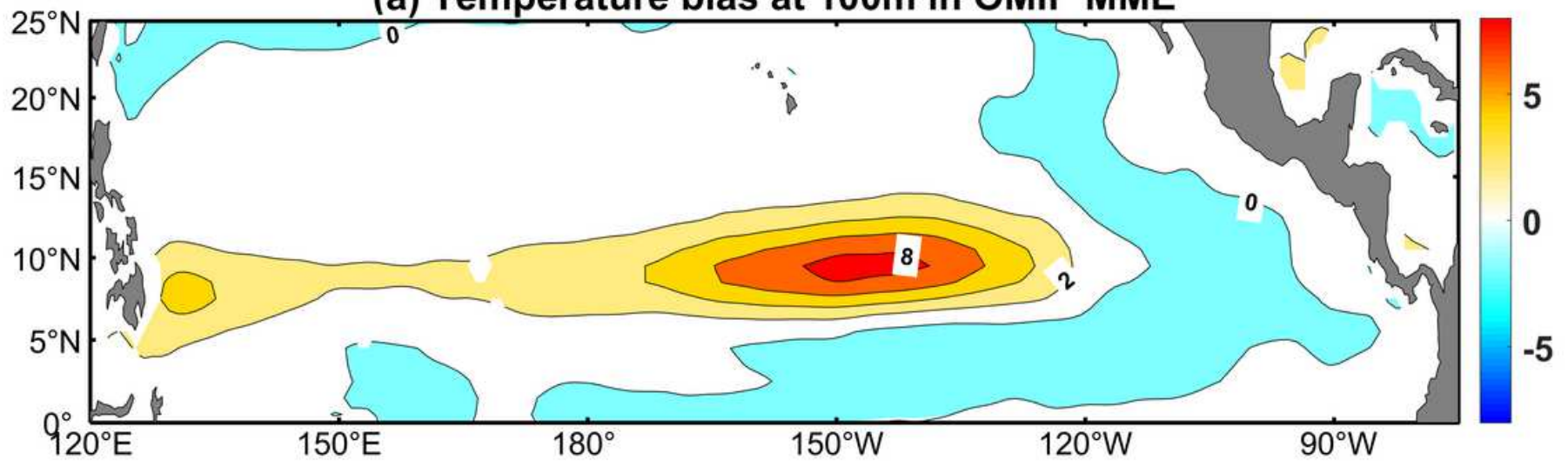

(b) WSC diff between OMIP MME and ERA5

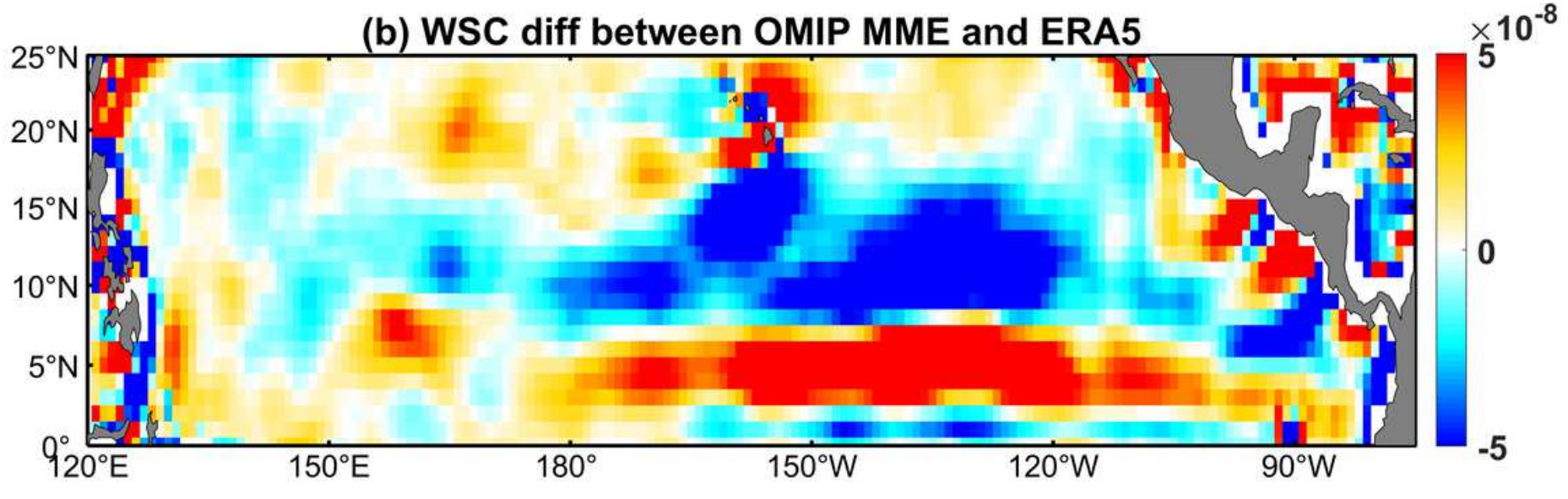

Figure 5

(a) SWB [ $\left.{ }^{\circ} \mathrm{C}\right]$ at the depth of $100 \mathrm{~m}$ in the OMIP MME. (b) The WSC difference [ $\mathrm{N} \mathrm{m}-3$ ] between the OMIP MME and the ERA5.

(a)

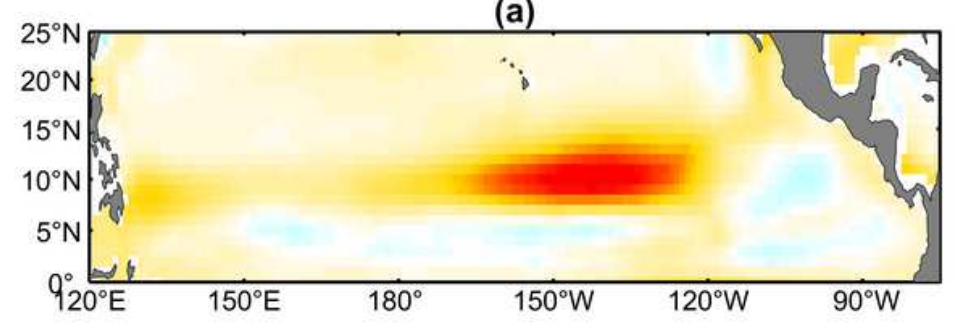

(c)

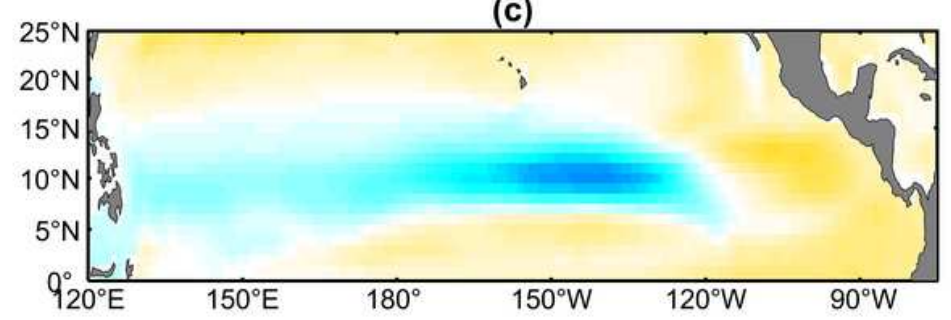

(b)

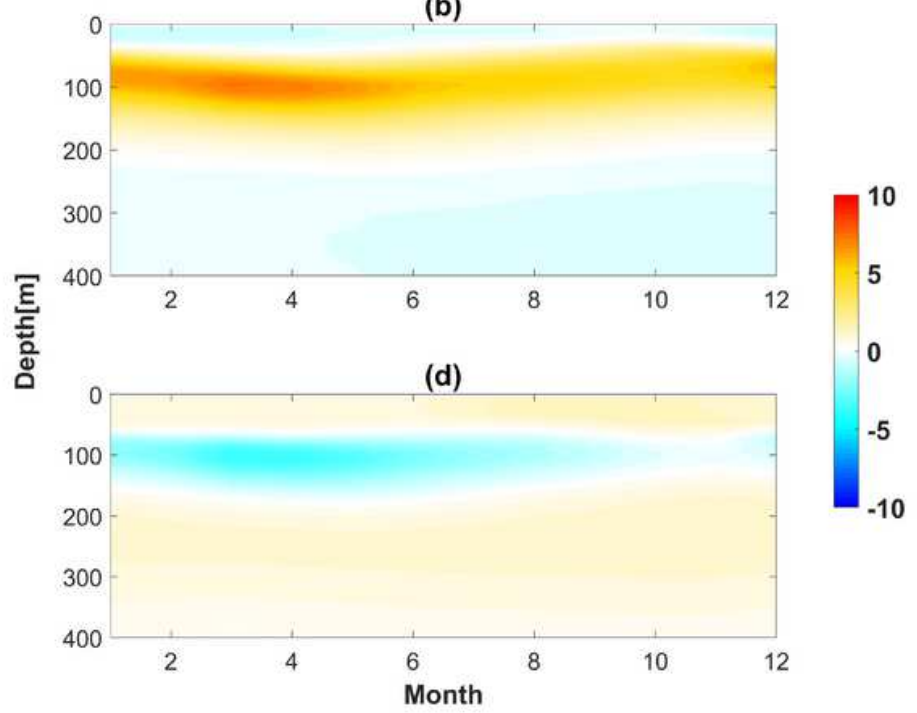

Figure 6 
(a) Temperature bias at the depth of $100 \mathrm{~m}$ and (b) the vertical-season section of temperature bias horizontally averaged over the NETP in the LY09 run. (c, d) The differences between the ERA5 run and the LY09 run.

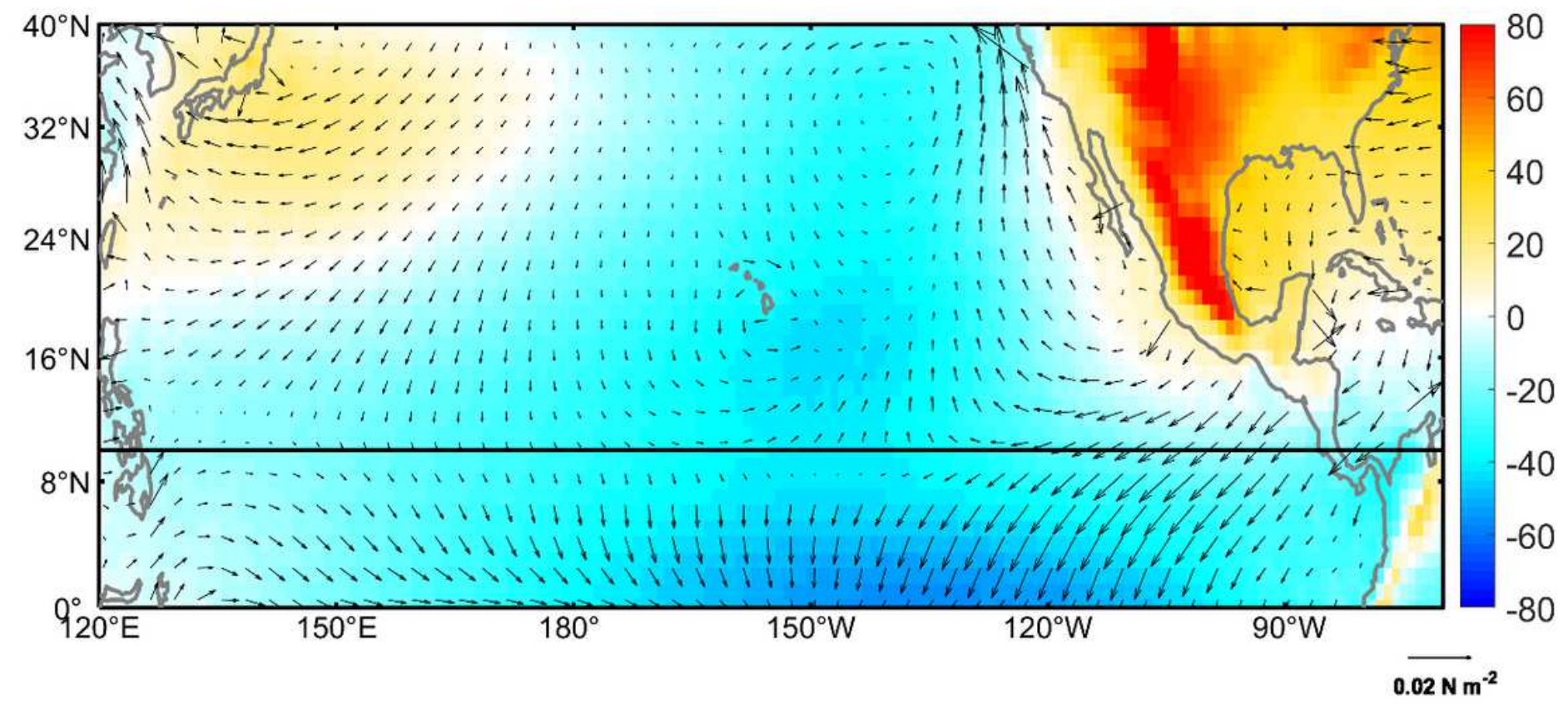

\section{Figure 7}

Linear regressions of the intermodel sea level pressure [color, $\mathrm{Pa}$ ] and wind stress vectors [N m-2] onto the normalized SWB.

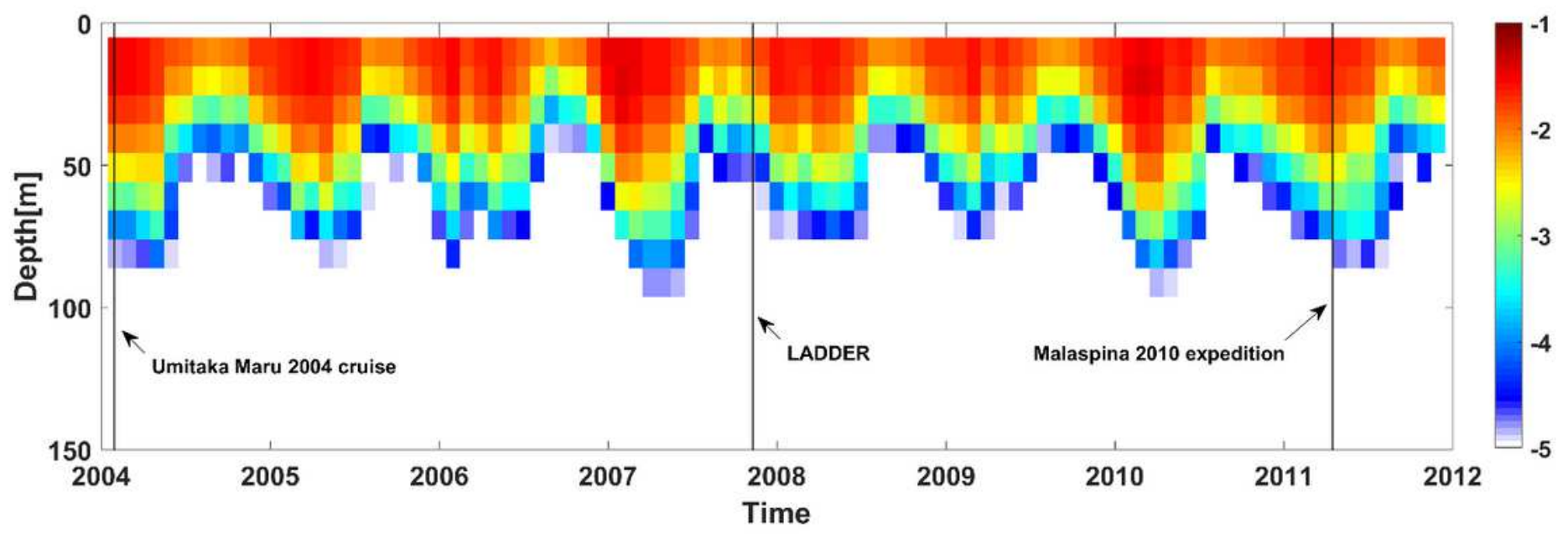

\section{Figure 8}

Base-10 logarithm of the vertical diffusivity (the averaged over $\left.\left(8^{\circ}-15^{\circ} \mathrm{N}, 110^{\circ}-150^{\circ} \mathrm{W}\right), \mathrm{m} 2 \mathrm{~s}-1\right)$ from the ocean-only experiment. Given the short period of the LY09 forcing fields (1948-2009), another OMIPrecommended forcing fields (Tsujino et al., 2018) spanning 1958-2018 are used to drive the MOM5. 
Model outputs for the vertical diffusivity from 2004-2012 are shown in colors, and three in-situ microstructure observations are indicated by the black lines.
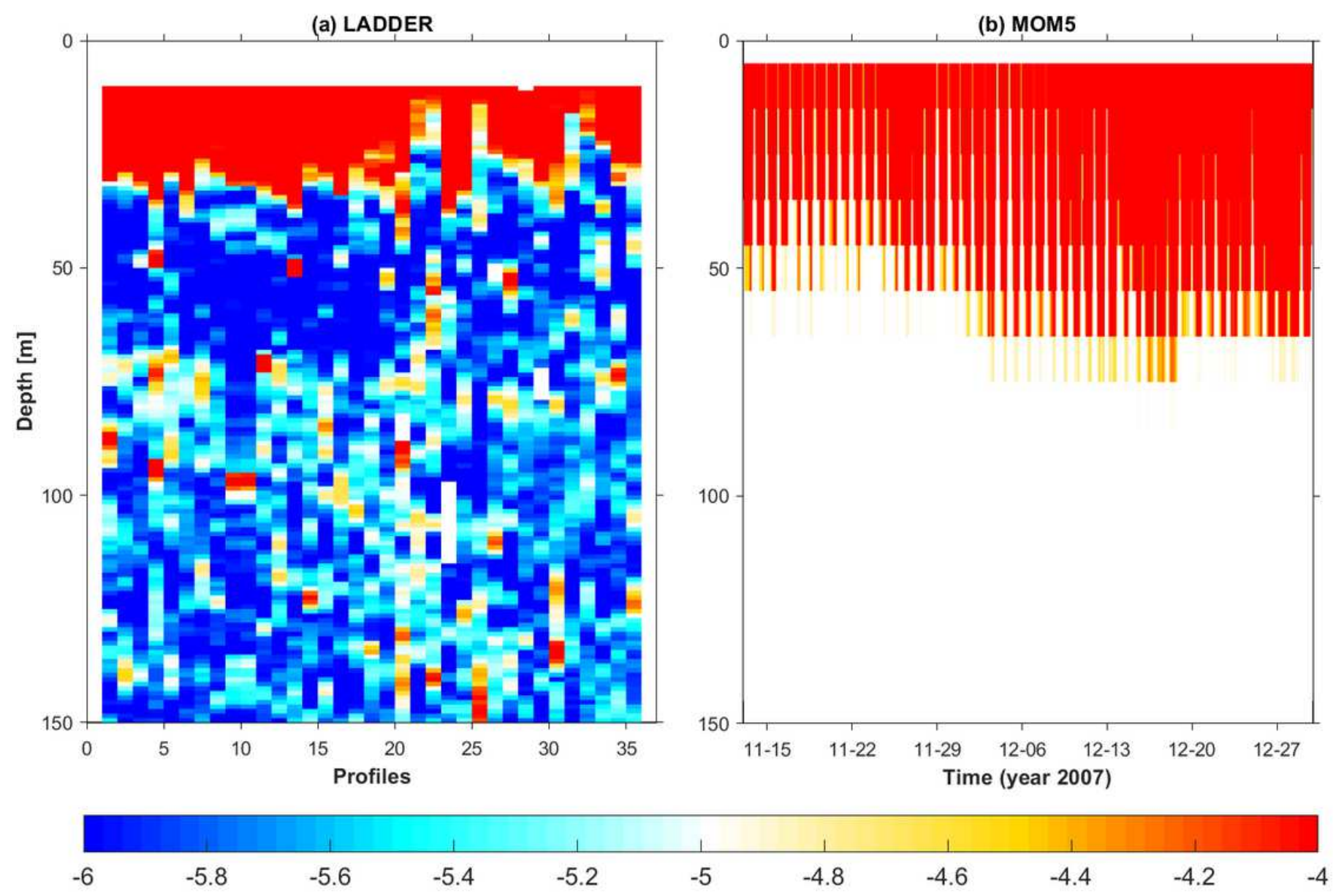

\section{Figure 9}

(a) Microstructure profiles from the LADDER project (kindly provided by Professor Andreas M. Thurnherr at Lamont-Doherty Earth Observatory). These data were collected in the eastern tropical Pacific near the crest of the East Pacific Rise $\left(9^{\circ} 30^{\prime}-10^{\circ} \mathrm{N}, 103^{\circ} 45^{\prime}-105^{\circ} \mathrm{W}\right)$ using Vertical Microstructure Profiler (VMP) during November to December, 2007. (b) The corresponding vertical diffusivity in MOM5 based oceanonly simulation. 


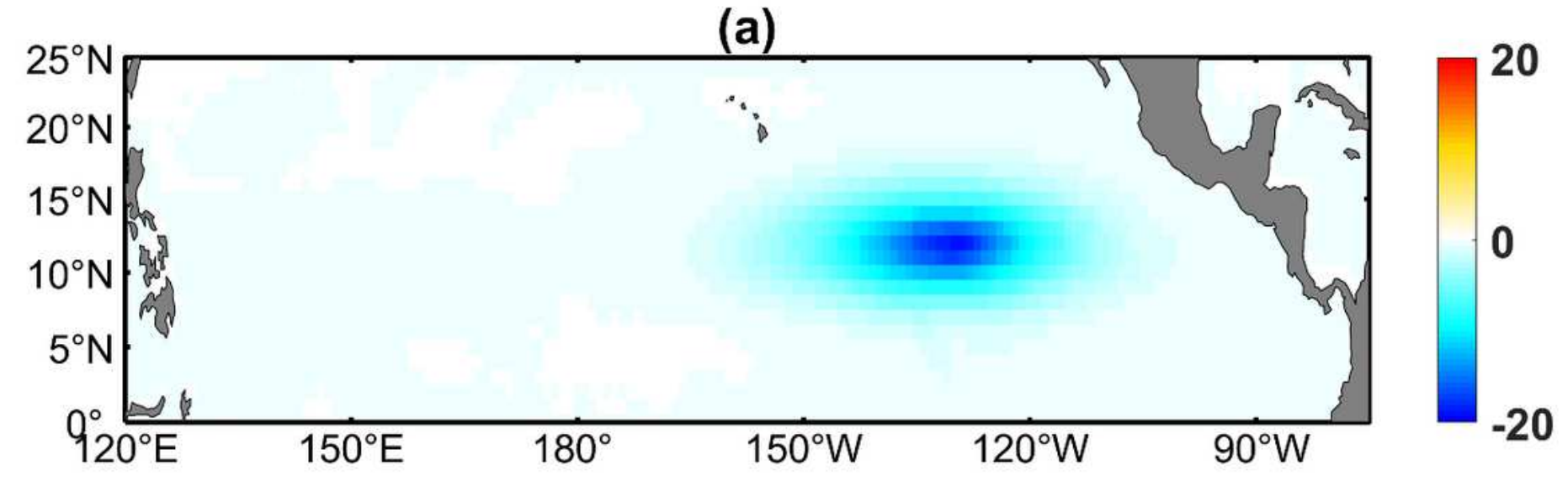

(b)

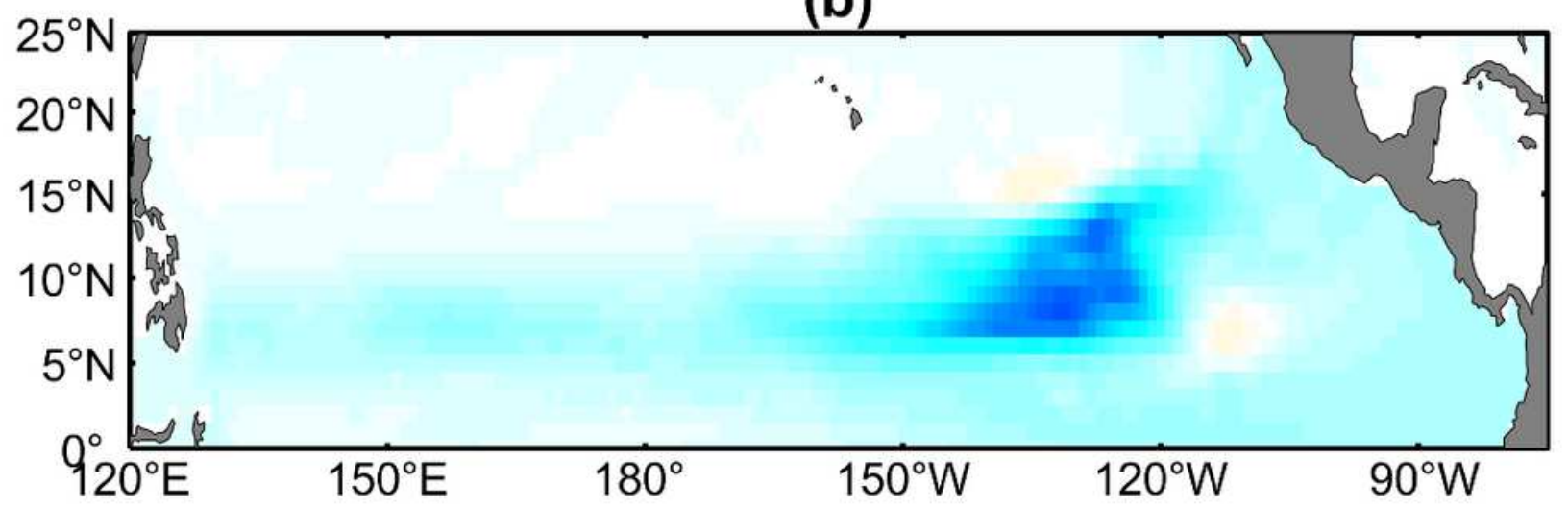

(c)

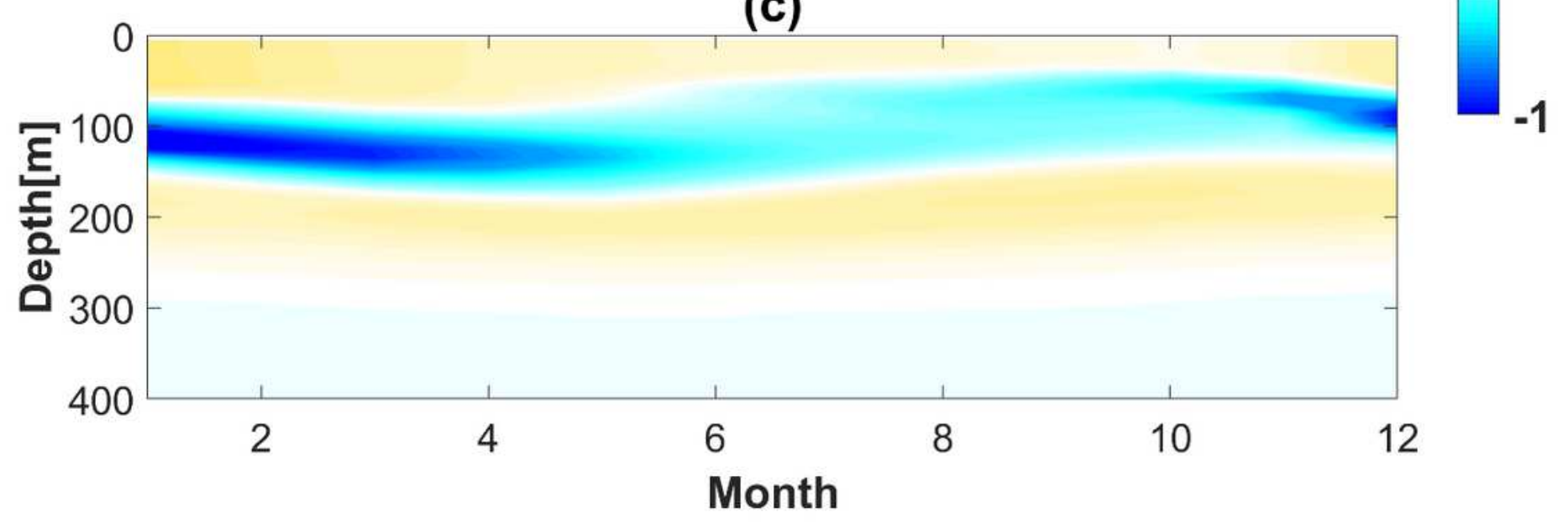

Figure 10

Annual-mean differences in (a) ocean surface boundary layer [m] and (b) temperature at the depth of 100 $\mathrm{m}\left[{ }^{\circ} \mathrm{C}\right]$ between the reduced $\mathrm{m} 0$ run and the control run. (c) Vertical-season section of temperature difference horizontally averaged over the NETP. 

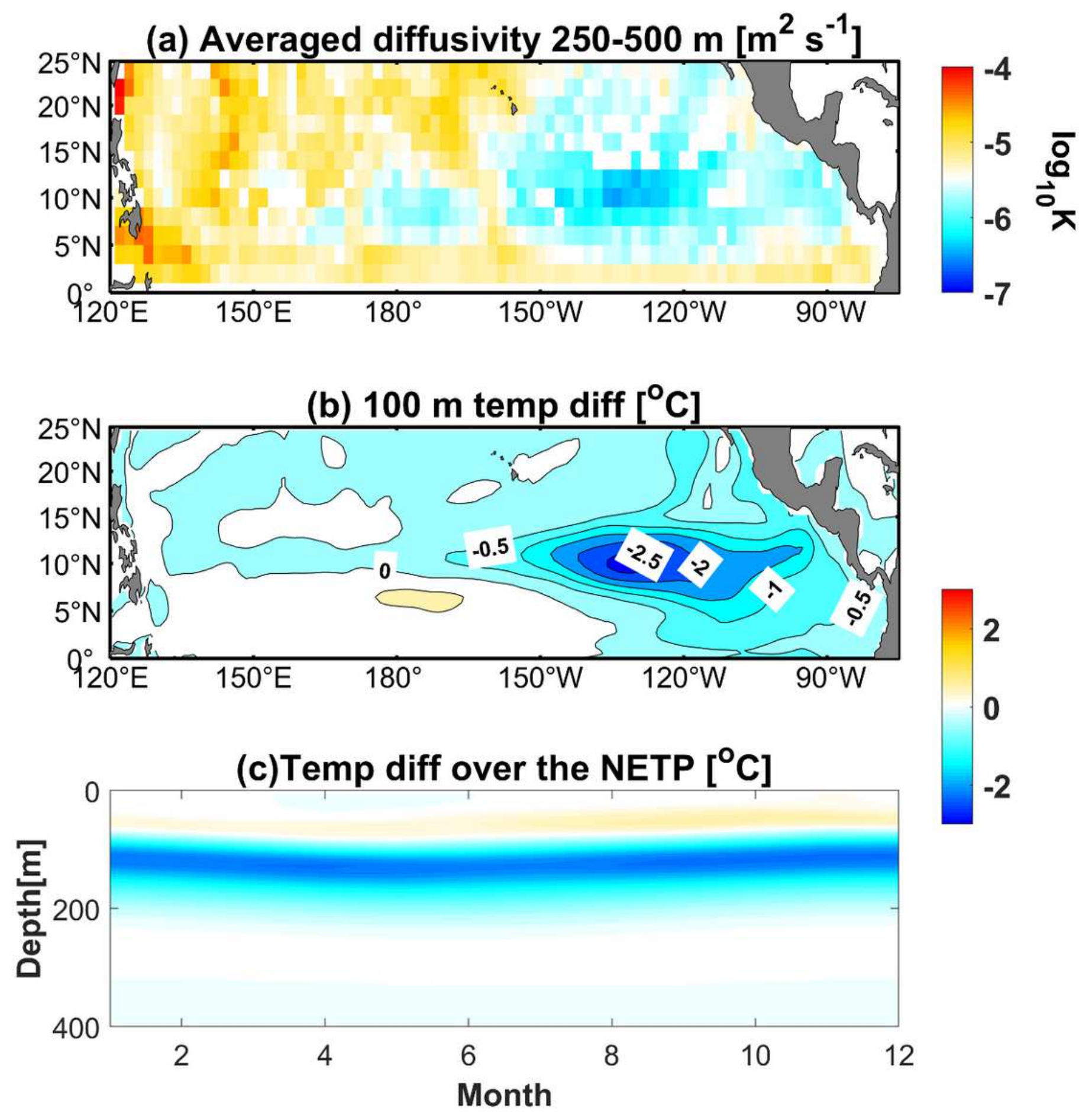

Figure 11

(a) Diapycnal diffusivity estimated based on the finescale parameterization using the Argo profiles (available online at ftp://ftp.ifremer.fr/ifremer/argo/) with 2-10 m vertical resolution and from 2006 to 2019. (b, c) The temperature differences between the RBD run and the control run. 
(a)

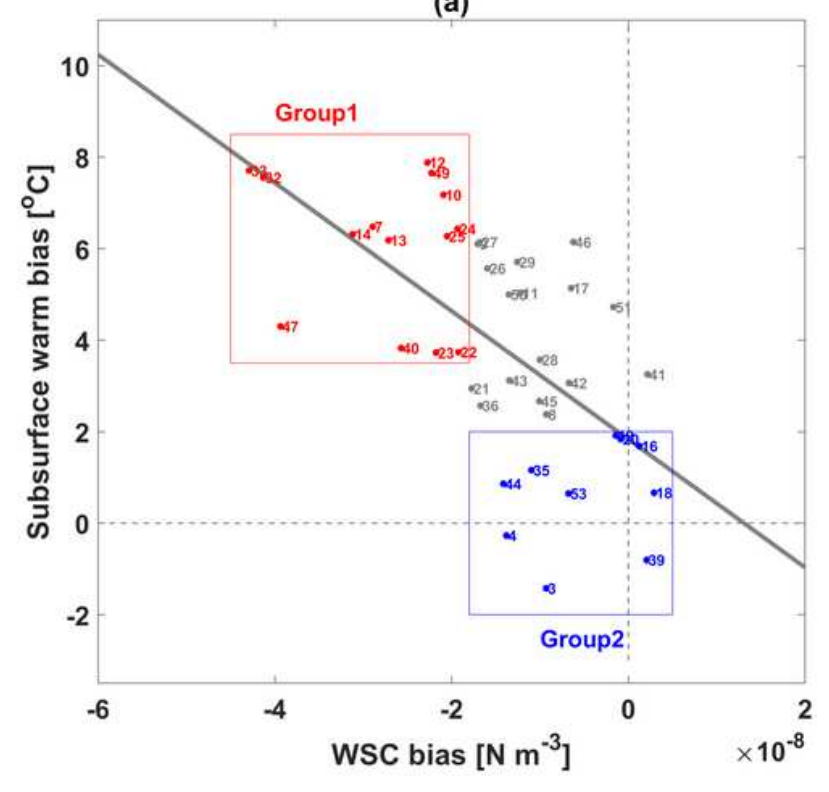

(b) $5^{\circ} \mathrm{N}$

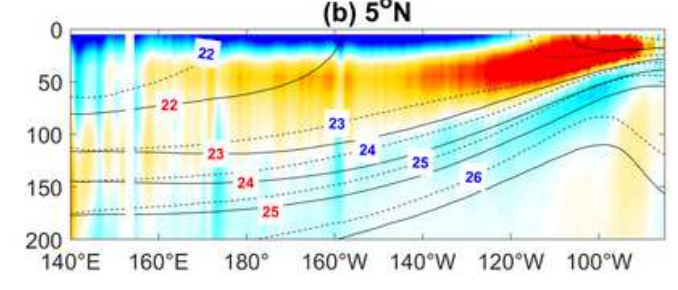

(c) $10^{\circ} \mathrm{N}$

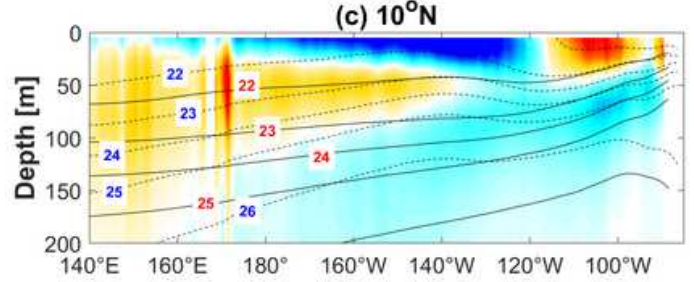

(d) $15^{\circ} \mathrm{N}$

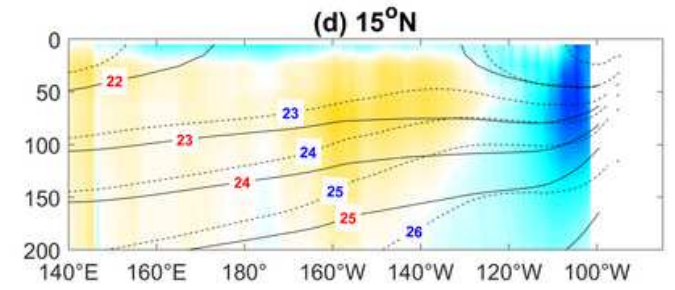

Figure 12

(a) Two model groups classified in terms of the SWB magnitude. Models in the Group1 have large SWB, while SWB in the Group2 is trivial. (c-d) Meridional velocity differences between the Group1 and Group2 [colors, cm s-1], and potential density [kg m-3] in Group1 MME (solid lines) and Group2 MME (dashed lines) along $5^{\circ} \mathrm{N}, 10^{\circ} \mathrm{N}$ and $15^{\circ} \mathrm{N}$, respectively. 
(a) Group1

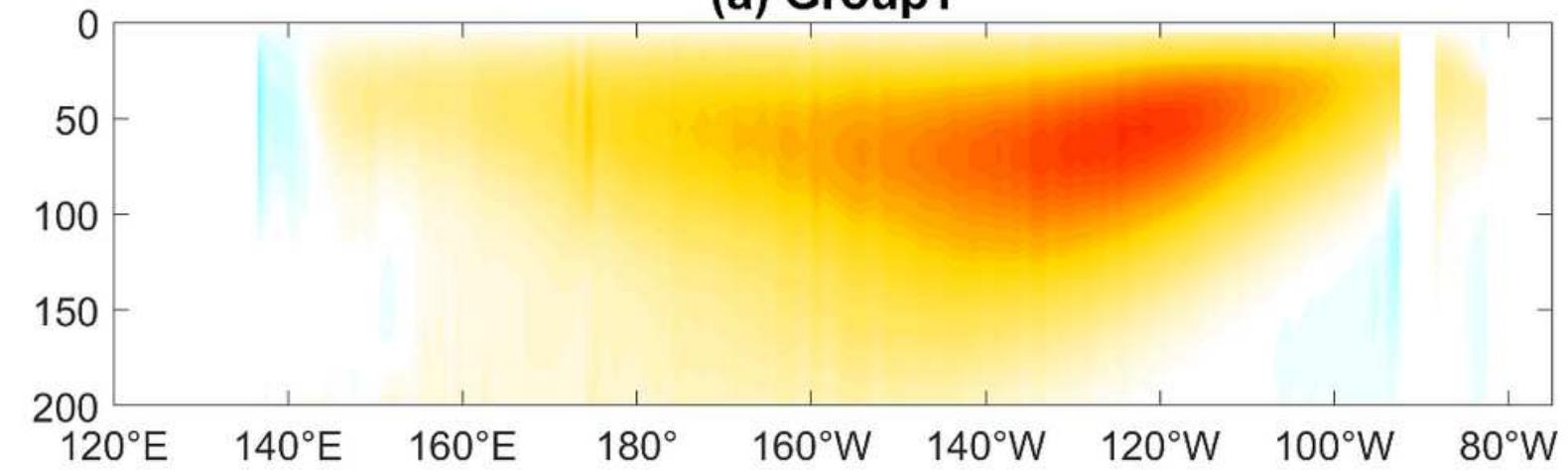

(b) Group2

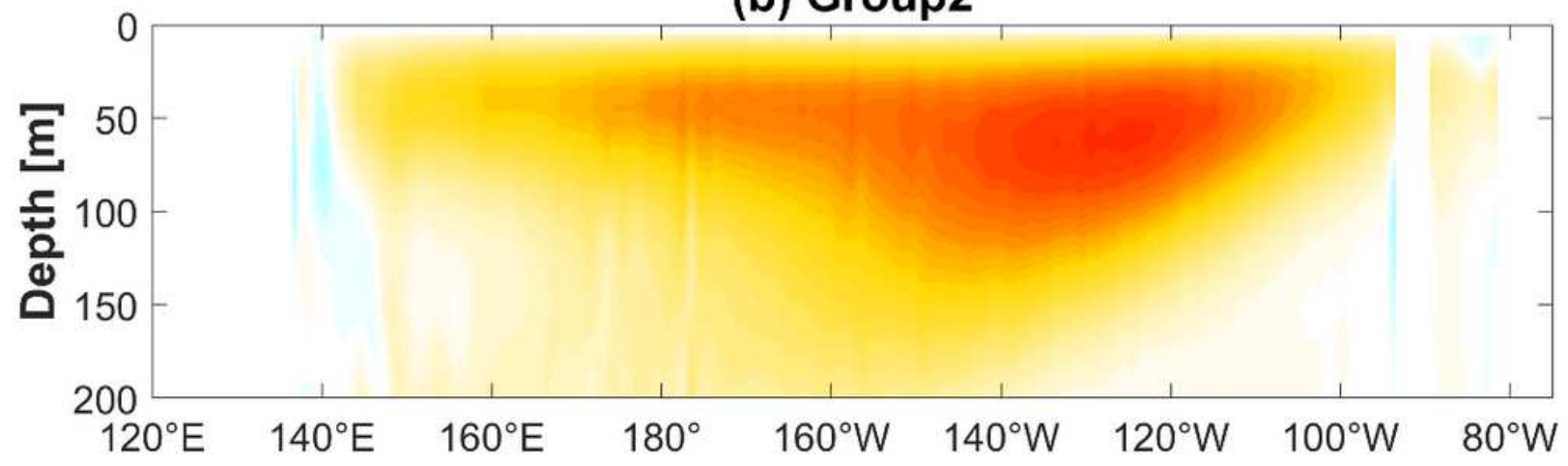

(c) Diff (G1-G2)
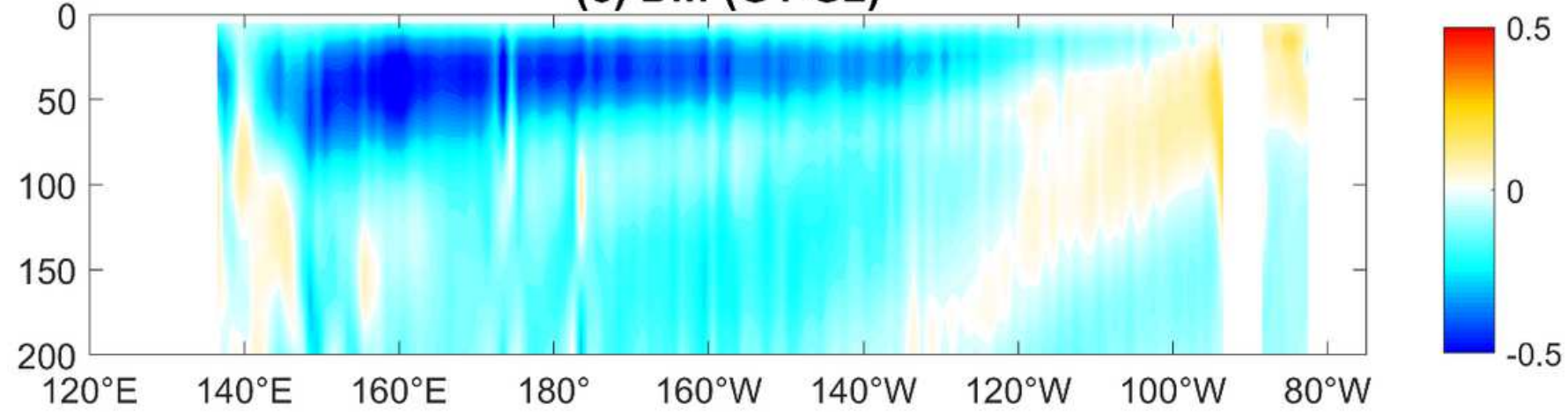

Figure 13

Vertical velocity [m day-1] along the equator in the (a) Group1 MME and (b) Group2 MME. (c) The difference between Group1 and Group2. 

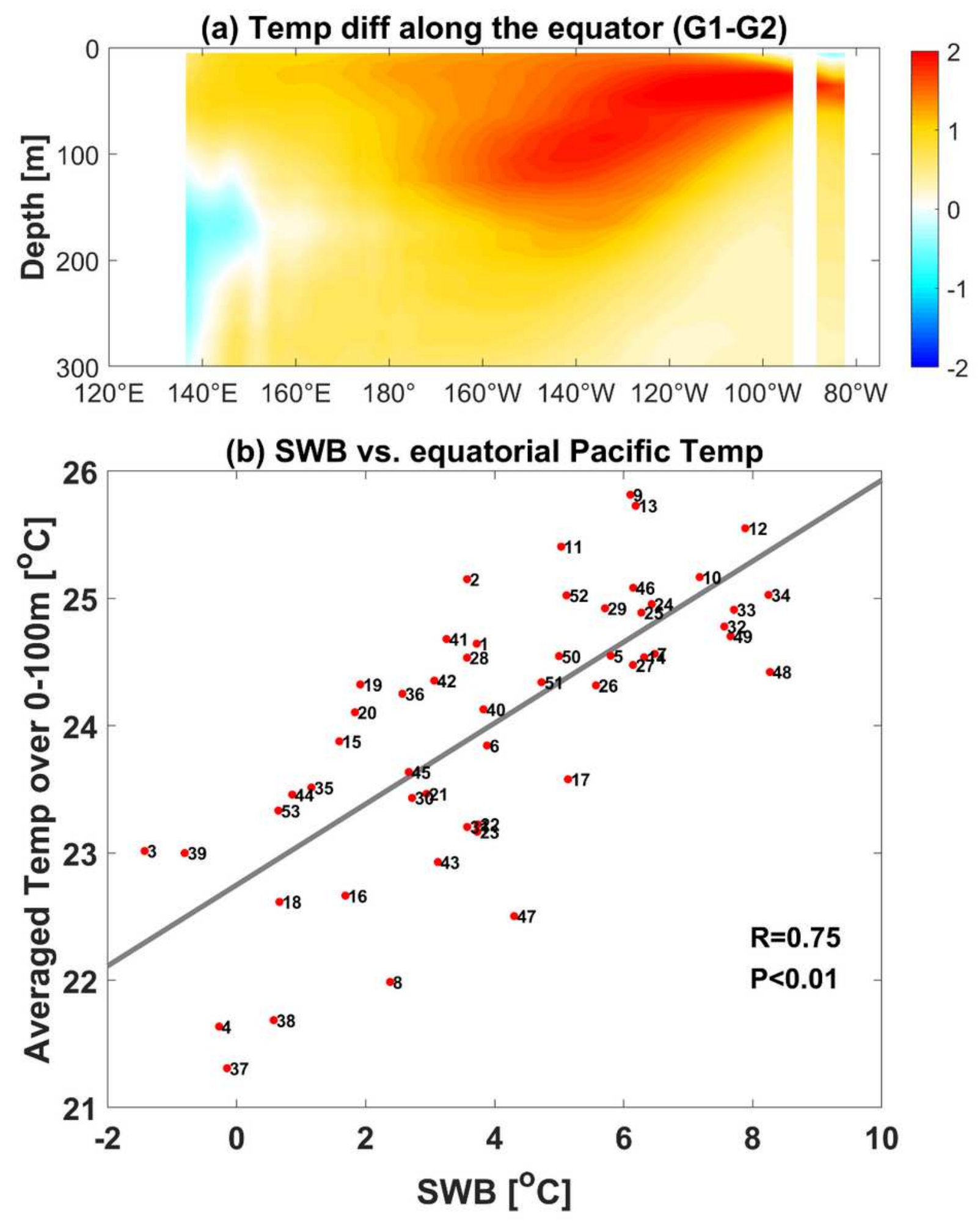

Figure 14

(a) Temperature differences $\left[{ }^{\circ} \mathrm{C}\right]$ along the equator between the Group1 and Group2. (b) Scatterplots of the relationship between the SWB and the equatorial Pacific temperature averaged over $\left(0-100 \mathrm{~m}, 140^{\circ} \mathrm{E}-\right.$ $\left.80^{\circ} \mathrm{W}\right)$. 

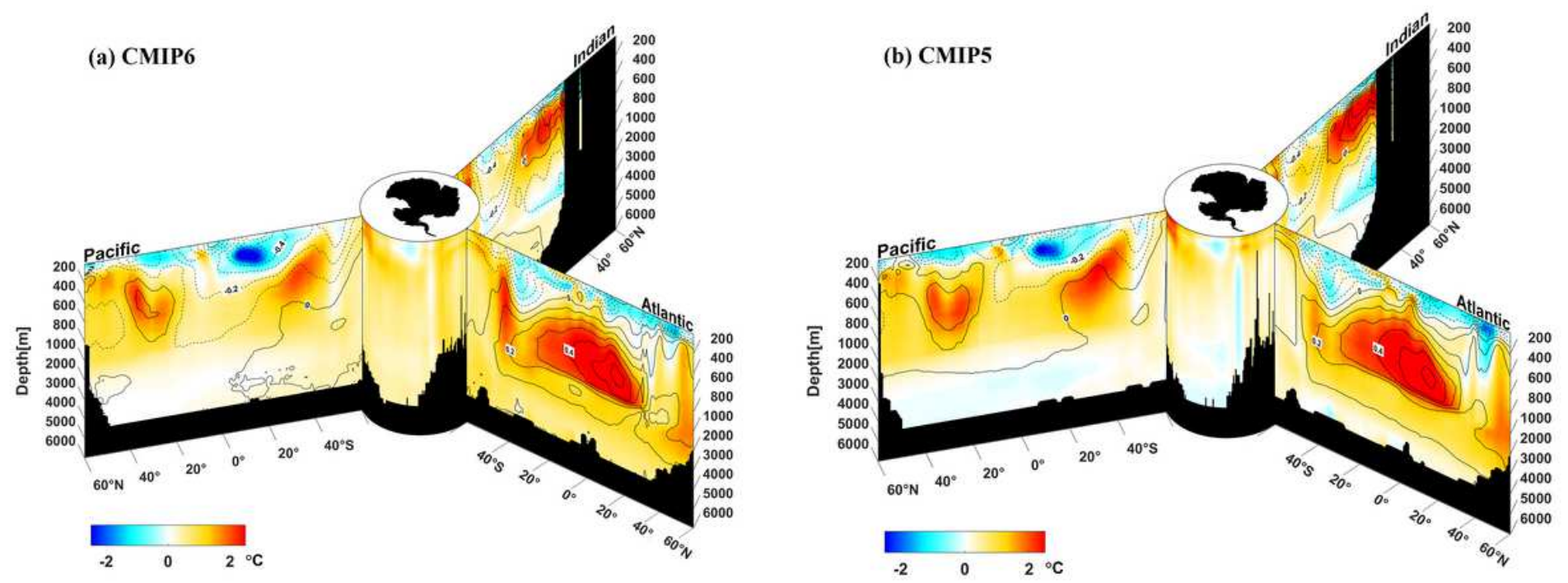

Global distribution of thermohaline bias

\section{Figure 15}

The basinwide zonally averaged biases for temperature (colors) and salinity (contours) biases in (a) CMIP6 and (b) CMIP5. 